\title{
Effect of Myelin Oligodendrocyte Glycoprotein (MOG35-55) on Cell Differentiation and Abzymes Production in Transgenic EAE-Prone Th Mice with T Cells Response During the Development of Experimental Encephalomyelitis
}

\section{Kseniya Aulova}

Institute of Chemical Biology and Fundamental Medicine Siberian Branch of the Russian Academy of Sciences: Institut himiceskoj biologii i fundamental'noj mediciny Sibirskogo otdelenia Rossijskoj akademii nauk

\section{Andrey Urusov}

Institute of Chemical Biology and Fundamental Medicine Siberian Branch of the Russian Academy of Sciences: Institut himiceskoj biologii i fundamental'noj mediciny Sibirskogo otdelenia Rossijskoj akademii nauk

\section{Ludmila Toporkova}

Institute of Clinical imminology

\section{Sergey Sedykh}

Institute of Chemical Biology and Fundamental Medicine Siberian Branch of the Russian Academy of Sciences: Institut himiceskoj biologii i fundamental'noj mediciny Sibirskogo otdelenia Rossijskoj akademii nauk

\section{Yuliya Shevchenko}

Institute of Clinical Immunology

Valery Tereshchenko

Institute of Clinical Immunology

\section{Sergey Sennikov}

Institute of Clinical Immunology

\section{Thomas Budde}

Westfalische Wilhelms-Universitat Munster

\section{Sven Meuth}

Clinic fur neurologie, Dusseldorf Irina Orlovskaya Institute of Clinical immunology

Georgy Nevinsky ( $\square$ nevinsky@niboch.nsc.ru ) 
Institute of Chemical Biology and Fundamental Medicine Siberian Branch of the Russian Academy of Sciences: Institut himiceskoj biologii i fundamental'noj mediciny Sibirskogo otdelenia Rossijskoj akademii nauk https://orcid.org/0000-0002-4988-8923

\section{Research article}

Keywords: Transgenic Th mice with T lymphocytes response, Experimental autoimmune encephalomyelitisDevelopment, Hematopoietic stem cells differentiation, Lymphocyte proliferation in different organs, Catalytic antibodies

Posted Date: July 13th, 2021

DOI: https://doi.org/10.21203/rs.3.rs-541620/v1

License: (c) (i) This work is licensed under a Creative Commons Attribution 4.0 International License. Read Full License 


\section{Effect of myelin oligodendrocyte glycoprotein $\left(\mathrm{MOG}_{35-55}\right)$ on cell differentiation and} abzymes production in transgenic EAE-prone Th mice with $\mathrm{T}$ cells response during

Kseniya S. Aulova ${ }^{1}$, Andrey E. Urusov ${ }^{1}$, Ludmila B. Toporkova ${ }^{2}$, Sergey E. Sedykh, Yuliya A. Shevchenko ${ }^{2}$, Valery P. Tereshchenko ${ }^{2}$, Sergei V. Sennikov ${ }^{2}$, Thomas Budde ${ }^{3}$,

*Correspondence to: Prof. Georgy A. Nevinsky, Institute of Chemical Biology and Fundamental Medicine of Siberian Branch of Russian Academy of Sciences; Novosibirsk 630090, Lavrentiev Ave. 8, Russia. Tel.: +7-383-3635126, Fax: +7-383-3635153, E-mail: nevinsky@niboch.nsc.ru

\section{Abstract}

Background: The mechanisms of multiple sclerosis development are still unknown. It was shown that the development of experimental autoimmune encephalomyelitis (EAE) in EAE prone C57BL/6 mice (model mimicking human multiple sclerosis) having B and T lymphocyte responses is associated with modification in the differentiation profiles of bone marrow hematopoietic stem cells (HSCs) and the increase in lymphocyte proliferation.

Methods: Only $\mathrm{T}$ cell responses characterize other EAE transgenic prone Th mice. Different characteristics of the autoimmune reaction in Th mice were analyzed. During the development 
of EAE (and inflammation processes), the differentiation profiles of Th mice bone marrow HSCs (BFU-E, CFU-E, CFU-GM, CFU-GEMM, T, and B lymphocytes) were noticeably or significantly different in male and female mice before and after their immunization with myelin oligodendrocyte glycoprotein $\left(\mathrm{MOG}_{35-55}\right)$.

Results: The patterns of B and T (including CD4 and CD8 cells) lymphocytes proliferation in several organs (spleen, thymus, bone marrow, blood, and lymph nodes) during spontaneous (completely untreated mice) and MOG-treatment-accelerated development of EAE was also remarkably or significantly different in male and female mice. All these changes in male and female mice, despite some differences, were coupled with the increase in the concentrations of autoantibodies against DNA, myelin basic protein, and MOG, and with the increase in the relative activity of catalytic antibodies hydrolyzing these antigens.

Conclusions: A comparison of the changes in a large number of parameters characterizing the development of EAE in Th and C57BL/6 mice was carried out. It was shown that MOG very much accelerates the development of EAE in Th mice with T cell responses. Despite some differences, the general patterns of the developing of spontaneous and MOG-accelerated EAE in Th male and female mice and in C57BL/6 mice are similar to a notable extent.

Keywords: Transgenic Th mice with T lymphocytes response; Experimental autoimmune encephalomyelitisDevelopment ; Hematopoietic stem cells differentiation; Lymphocyte proliferation in different organs, Catalytic antibodies

\section{Background}

Multiple sclerosis (MS) is the pathology of the central nervous system (CNS) related to an

57 increase in $\mathrm{T}$ lymphocytes and macrophages. The precise route of multiple sclerosis is unknown [1]. Different studies support the essential role of the destruction of myelin due to autoimmune (AI) reactions and inflammation processes. The activated myelin-active

$60 \mathrm{CD}^{+}$cells could be mediators of MS. Some findings also confirm the critical role of B 
61 cells and autoantibodies (auto-Abs) to various myelin autoantigens in MS pathogenesis [1-

62

$3]$.

The increased amounts of autoantibodies and the stockpiling of B cells in the bone marrow cerebrospinal fluid (CSF), as well as the MS patient's typical lesions, ensure key evidence for the demyelination involvement in the humoral response [4]. Studies of MS animal models indicate auto-Abs against myelin components are involved in Absdependent demyelination [3]. Autoantibodies against cell protein-oligodendrocyte progenitors could interfere with remyelination by removing or obstructing these cells [5].

Autoimmune diseases (AIDs) were first being proposed are originated from hematopoietic stem cells (HSCs) defects [6]. Later, it was identified that the spontaneous (without mice immunization with any antigens), as well as antigen-induced development of EAE in C57BL/6 [7,8] and in MRL-lpr/lpr mice of systemic lupus erythematosus (SLE) [9$11]$, is reached due to specific immune reorganization of bone marrow hematopoietic stem cells. The bone marrow immune system defects include specific parallel changes in the profile of differentiation of bone marrow HSCs and the production of catalytic autoantibodies-abzymes splitting DNA, RNA, polysaccharides, proteins, and peptides. The detection of Abs with catalytic activities is the statistically most significant and earliest marker of many AIDs in humans and animals [12-17] as well as in SLE [18-20], EAE [7,8], and MS [21-28]. Enzymatic activities of abzymes are well detected at the very initial stages of the diseases (at the pre-disease onset stage) before the emerging of typical markers of different AIDs [13-17]. Titers of auto-Abs to various auto-antigens at the onset of different AIDs usually correspond to typical indices' ranges corresponding to healthy humans and experimental mice. The appearance of multiple abzymes clear indicates the start of AIDs, while an increase in their enzymatic activities is associated with deep pathologies development. However, different AIDs development might be mediated by 
several mechanisms, eventually leading to a self-tolerance breakdown and inflammation

87 processes.

88 Several EAE models mimic particular aspects of human MS, including C57BL/6 mice 89 (for a review, see [29-32]). In C57BL/6 mice, EAE passes as a spontaneous chronicprogressive disease. These mice show the specific $\mathrm{T}$ and $\mathrm{B}$ lymphocyte responses to antigens [29-32]. C57BL/6 mice were used to analyze eventual mechanisms of spontaneous DNA- and myelin oligodendrocyte glycoprotein ( $\mathrm{MOG}_{35-55}$ )-dependent acceleration of EAE development [7,8]. These mice's immunizations with $\mathrm{MOG}_{35-55}$ or DNA led to a speed-up of EAE development, associated with parallel specific changes in the profiles of differentiation of bone marrow HSCs, lymphocyte proliferation, and autoAbs production possessing myelin basic protein (MBP)-, MOG-, and DNA-hydrolyzing activities.

Another Th model corresponding to spontaneous EAE autoimmunity of CNS exists. This model was obtained due to crossing transgenic mice with a particular myelin-specific T-cell receptor (TCR) and mice specific for myelin-specific immunoglobulin heavy chain knock-in mice and described in [33]. Th mice demonstrate $\mathrm{T}$ cell responses to various

102 antigens and primarily MOG, resulting in the spontaneous and stimulated development of a

103 severe EAE. It is important to understand all possible complementary parallel mechanisms of disease to explain how MS and EAE develop.

105 Here, we have carried out for the first time the analysis of many different parameters,

106 including abzymes, characterizing accelerated development of EAE after Th mice 107 immunization with MOG, and compared the features of the development of pathology 108 before and after the mice immunization. In addition, the same parameters were 109 compared for Th mice with T-response and C57BL/6 with $\mathrm{T}$ and B-cell responses 110 before and after mice immunization with MOG at different stages of EAE development. 


\section{Results}

\section{Choosing a model for studying EAE development}

$114 \mathrm{~T}$ and B lymphocytes play vitally important roles in the pathogenesis of human MS [1] and

115 animals EAE [29-32]. B cells provide Abs important for the humoral immunity of the 116 adaptive immune system [32]. In the bone marrow, mature B cells have membrane

117 receptors allowing them to interact with different antigens leading to the initiation of the

118 Abs response. Spontaneous and MOG-accelerated EAE in C57BL/6 mice are characterized

119 by both $\mathrm{T}$ and $\mathrm{B}$ cell responses [29-32]. C57BL/6 mice spontaneous development of EAE

120 associates with slow changes in HSCs differentiation profiles parallel with an increase in

121 the level of lymphocyte proliferation in various organs during the initial 2-3 months

$122[7,8,34,35]$. These mice's changes lead to the parallel production of abzymes hydrolyzing

123 MOG, MBP, and DNA [7,8,34,35]. Immunizing C57BL/6 mice with MOG accounts for a

124 powerful acceleration of EAE development with the onset and acute phases appearing at 7

125 and 14-20 days after immunization, respectively [7,8,29-32,34,35]. During these phases,

126 there was observed an increase in concentrations of auto-Abs and the appearance of abzymes

127 hydrolyzing DNA, MBP, and MOG. Such abzymes are very dangerous for mammals.

128 Abzymes with DNase activity can penetrate through cellular and nuclear membranes,

129 cleavage DNA of chromatin, and induced cell apoptosis [36-38]. This process results in an

130 increase in blood concentration of DNA complexes with histones, which are the most

131 important antigens in the production of Abs against DNA and histones [39]. Abzymes

132 splitting MBP and MOG hydrolyze these components of nerve tissue membranes, leading

133 to an impaired nerve impulse [13-19,21-23].

134 In contrast to EAE prone C57BL/6 mice having $\mathrm{T}$ and $\mathrm{B}$ cell responses [29-32],

135 transgenic EAE prone Th mice are characterized by a $\mathrm{T}$ cell response [33]. Therefore, it

136 was interesting to compare various parameters characterizing the spontaneous and MOG-

137 accelerated development of EAE in Th and C57BL/6 mice. In the case of C57BL/6 mice, 
138 there was analyzed the development of EAE using only male mice $[7,8,34,35]$. However,

139 multiple sclerosis is less common for men than for women [40]. Only about a third of

140 patients with MS are men, and the rest are women. In addition, the disease often occurs

141 quite late in men and proceeds more severely.

142 Therefore, taking this into account, in this study, we compared the development of

143 EAE after immunization with MOG of male and female Th mice. In addition, to compare

144 specific features of the EAE development in mice with $\mathrm{T}(\mathrm{Th})$ response and $\mathrm{T}$ and $\mathrm{B}$

145 (C57BL/6) responses, some previously obtained data on the analysis of C57BL/6 male mice 146 were used $[7,8,34,35]$.

\section{Weight and proteinuria of EAE mice}

149 We have first analyzed over time changes in the relative weight of Th mice before and

150 after they immunization with MOG (Fig. 1a). Interestingly, the immunization of male

151 and female mice with MOG had minimal effect on their weight over time compared

152 with the untreated mice. After the immunization, a decrease in weight of C57BL/6

153 males during 10-15 days (Supplementary S1; all supplementary Figs are given in

154 Supplementary data) was more pronounced than in Th males (Fig. 1a).

155 Development of autoimmune pathologies in different autoimmune prone mammals, 156 including MRL-lpr/lpr [9-11] and C57BL/6 mice [7,8,34,35], is characterized by

157 proteinuria ( $3 \mathrm{mg} / \mathrm{ml}$ concentration of protein in urine). Non-autoimmune CBA and BALB

158 mice at least during 12 months demonstrated the absence of proteinuria $(0.1-0.12 \mathrm{mg} / \mathrm{ml})$

159 [9-11]. Autoimmune-prone healthy MRL-lpr/lpr mice before the development of SLE are 160 characterized by low proteinuria $(0.38 \mathrm{mg} / \mathrm{ml})$ [9-11]. However, C57BL/6 male mice have 161 demonstrated a higher level of protein concentration in urine (up to $10-12 \mathrm{mg} / \mathrm{ml}$ ) $162[7,8,34,35]$. 
164 with MOG were analyzed (Fig. 1b). At time zero (3 months of age) in two groups of seven

165 male and female mice before their immunization, the average urine protein concentration

166 was surprisingly very different: $7.6 \pm 2.2$ and $3.2 \pm 1.0 \mathrm{mg} / \mathrm{ml}(P<0.05)$, respectively (Fig.

167 1b). During the spontaneous development of EAE, the concentration of proteins in the 168 urine of Th males increased 1.6 times (to $12 \mathrm{mg} / \mathrm{ml}$ ), while in females, only 1.3 times (to $1694.2 \mathrm{mg} / \mathrm{ml})$; the difference in concentration is statistically significant $(P=0.01)$. After 170 immunization of male mice, proteinuria was increased up to day 43, similar to its growth 171 before mice treatment, and then it began to decreased (Fig. 1b); the difference is 172 statistically significant $(P=0.01)$. In contrast to Th male mice, the immunization of

173 C57BL/6 male mice led to a relatively flowing 1.8-fold increase in proteinuria after immunization compared with the spontaneous development of EAE (Supplementary Fig. S1). A completely different situation was observed in Th female mice having at zero time lower proteinuria. In female mice from 15 to 30 days, proteinuria was sharply increased 3.2-fold (to $10.3 \mathrm{mg} / \mathrm{ml}$ ) and then was decreased (Fig. 1b). Thus, the immunization with MOG differently affects the proteinuria of female and male mice, which might be possibly associated with some specific features of EAE development in Th female and male mice.

\section{Hematopoietic progenitor colony formation}

182 It was shown that the differentiation profile of bone marrow stem cells in CBA and BALB

183 mice not predisposed to AIDs does not remarkably change for at least 1-2 years [9-11]. It 184 was shown that spontaneous in-time development of EAE in C57BL/6 mice (change in the analyzed parameters of EAE in time before immunization of mice) results in significant

186 changes in the differentiation profile of bone marrow stem cells $[7,8,34,35]$. Therefore, we

187 first performed carried out a parallel analysis of possible changes in the stem cell 188 differentiation profiles of three-month-old EAE prone Th mice ( 7 males and 7 females; the 
maximum number of mice, which it was possible to analyze in such parallel experiments).

190 During the 80 days of MOG-induced EAE development, a significant increase in the

191 relative number of BFU-E colonies occurred in the bone marrow of Th male and female

192 mice in the period from 15 to 40 days (Fig. 2a). In the beginning, there was 2.0-fold

193 difference $(P<0.05)$ between BFU-E colonies of male and female mice, but during the

194 entire analysis period of EAE development did not differ significantly $(P=0.19)$ except

195 1.8-fold difference $(P<0.05)$ at day 42. Simultaneously, during the spontaneous

196 development of EAE, the relative number of these colonies gradually decreases (Fig. 2a),

197 demonstrating a significant difference for male and female mice $(P=0.02)$.

198 Earlier, we analyzed the changes in the differentiation profile of HSCs in C57BL/6 male

199 mice with T- and B-responses. Interestingly, in male mice of C57BL/6 line, at the

200 spontaneous development of EAE, there are no significant changes in the number of BFU-

201 E colonies up to 20 days, while after immunization, it noticeably decreases (Supplementary

202 Fig. S2). After 20 days, the relative number of these colonies increases in both immunized

203 and untreated C57BL/6 male mice. Th male mice before immunization do not demonstrate

204 an increase, but a decrease in the number of these colonies over time, and after

205 immunization, the increase in the number of BFU-E colonies begins earlier, from about 10-

20615 days of experiments (Fig. 2a).

207 A significant difference in the direction of changes in CFU-E colonies was observed

208 between female and male Th mice during spontaneous EAE development (Fig. 2b). The

209 number of CFU-E colonies in male mice increases during 10 days and then slowly

210 decreases; only slight changes in the relative number of CFU-E colonies in Th female mice

211 are observed up to approximately day 35, and then their number remarkably increases.

212 There was no, however, the statistical difference in these average values during the

213 development of EAE in male and female mice $(P>0.05)$. Immunization with MOG leads

214 to a significant increase in CFU-E colonies in Th males and females with earlier and 
215 stronger growth of these colonies number in male mice (Fig. 2b). A statistically significant

$216 \sim 2$-fold difference $(P<0.05)$ in the number of colonies in males and females after their

217 immunization with MOG was observed in the period from 14 to 21 days (onset and acute

218 phase of EAE). Despite the significant difference in the profiles of changes in the relative

219 average number of CFU-E colonies during the entire experiment, the difference in the 220 colonies for female and male mice was insignificant, $P>0.05$.

C57BL/6 males showed a slow increase in the number of these colonies (Supplementary Fig. S2). Nevertheless, in the case of males of both Th and C57BL/6 lines, their immunization with MOG results in a sharp increase in the number of these colonies by days 10-20 (Figs 2b and Supplementary Fig. S2).

The change in the average number of CFU-GM colonies over time during spontaneous development of EAE in female and male Th mice is complex (Fig. 2c) and characterized by a significant difference $(P=0.012)$. There is a decrease in the CFU-GM colonies at 10 20 days, but a notable increase by day 35 and a further perceptible decrease. Th males showed an opposite change in the number of CFU-GM colonies before and after their 230 immunization with MOG demonstrating a maximal 2.7-3.0-fold $(P<0.05)$ difference from 23130 to 40 days. While before treatment, the number of colonies sharply decreased by $30-40$ days after immunization of male mice, their number decreased significantly from 10 and 50 days (Fig. 2c). No very significant changes were observed before immunization of Th

234 female mice, but after their immunization with MOG, a sharp increase in their number occurred by 30 days $(P=0.015)$. In other words, there is an oppositely directed change in the CFU-GM colonies in Th males and females after their immunization - in males, a sharp decrease, and in females, a powerful increase in the number of colonies. In contrast to a sharp increase before and a sharp decrease of CFU-GM colonies after Th males immunization with MOG (Fig. 2c), C57BL/6 males show a slow a gradual in time increase 
240 in their number during spontaneous and a slight decrease at day 10 during the MOG241 induced development of EAE (Supplementary Fig. S2).

242 For CFU-GEMM colonies of Th mice during spontaneous development of EAE, there were utterly opposite changes in the number of CFU-GEMM colonies for Th female and male mice: their number decreases in males but increases in female mice (Fig. 2d). At the same time, treatment of Th females and males with MOG led to a sharp 2.0-2.8-fold $(P<$ 0.05) decrease in the numbers of CFU-GEMM colonies for males at 30-40 days comparing with female mice (Fig. 2d). In C57BL/6 males, there were gradual in time changes in CFUGEMM colonies before and a faster decrease after their immunization (Supplementary Fig. S2).

The total amount of $\mathrm{T}$ and $\mathrm{B}$ cells in the bone marrow of Th female and male mice at the beginning of the experiment is significantly different (Figs 2e and 2f). Approximately the same 1.4-1.5-fold in time decrease in the number of B cells one can see for Th male and female mice $(P>0.05)$. There were observed overtime different character changes in the number of T cells in female and male mice bone marrow before immunization (Fig. 2f); the relative number of $\mathrm{T}$ cells decreases in males but increases in female mice $(P>0.05)$. After Th mice immunization with MOG, the number of B cells was significantly and comparable decreases in male and female mice from 7 to 30 days, and then it begins to increase, $P>0.05$ (Fig. 2e). After Th male and female mice immunization with MOG, a relative number of $\mathrm{T}$ cells was significantly decreases today 15 (Fig. 2f). Later the number

260 of T cells in the bone marrow of female mice continued to decrease smoothly. At the same 261 time, in Th male mice, there was a sharp increase in the number of T cells with a maximum 262 at day 23 (Fig. 2f). Overall, there was a statistically significant difference in T cells of bone marrow in male and female mice after their immunization $(P=0.005)$.

264 Thus, the changes observed in Th male and female mice during spontaneous 265 development of EAE are different for CFU-E, CFU-GEMM, and T cells but, to some 
extent, similar for BFU-E, CFU-GM, and B cells (Fig. 2). After immunization with MOG, some similarity in the change in the number of colonies is observed for BFU-E, CFU-E, CFU-GEMM, and B-cells but is opposite for CFU-GM colonies and T cells (Fig. 2).

269

\section{The content of $B$ and cells in various organs of mice}

271 Initially, we estimated, over time, relative average values characterizing the content of B 272 and T lymphocytes in bone marrow (Fig. 2) and then in other organs of Th male and 273 female mice before immunization and after their treatment with MOG.

274 The changes in relative amounts of B lymphocytes in different organs of mice are shown in

275 Fig. 3. The number of B cells over time in the blood of male mice at spontaneous 276 development of EAE grows smoothly and significantly faster for male than for female 277 mice (Fig. 3a). The maximum difference of 1.4 times $(P<0.05)$ is observed at 43 days 278 after the start of the experiment.

279 Immunization of Th mice with MOG leads to an approximately comparable strong increase in the number of B lymphocytes in the blood of males and female mice from 7 to 30 days, followed by a decrease in their number (Fig. 3a). At 7 days after immunization, the relative number of $\mathrm{B}$-cells in female is 1.3 times higher $(P<0.05)$ than in male mice.

The number of B lymphocytes growth in the thymus of female and male mice proceeds smoothly and almost similar (Fig. 3b). The curves of changes in the number of B lymphocytes in Th female and male mice after their immunization with MOG are very complex. At first, from 7 to 20 days, an increase in the number of B cells is observed (which is noticeably stronger in female mice) than a decrease (30-40 days) and again their growth (Fig. 3b). A very keen increase in the number of B-lymphocytes $(P<0.05)$ was observed in female mice at 22 days.

290 The complex patterns of changes in the number of B lymphocytes in the spleen and 291 lymph nodes of Th male and female mice were slightly different. During the first 7-16 
292 days, there was in both male and female mice a decrease in the number of B cells in the

293 spleen, but an increase in lymph nodes, followed by a slight rise in spleen but a decrease in

294 lymph nodes (Figs 3c and 3d). Mice immunization with MOG dramatically changed these

295 patterns. In male mice spleens, there was a sharp decrease in B lymphocytes by day 22 ( $P$

$296<0.05$ ), and then there was a remarkable increase in their relative content (Fig. 3c). In the

297 spleen of female mice, there was a constant but salutatory increase in B lymphocytes. The

298 patterns of reduction in B cells in the lymph nodes of male and female mice from 7 to 30

299 days after immunization mice with MOG were, to some extent, similar (Fig. 3d). After

300 immunization, there was a strong decrease of 2.3-2.4 times $(P<0.05)$ in the relative

301 number of B-lymphocytes in 15 days in female and 22 days in male mice (Fig. 3d).

302 Taken together, the curves of the changes in the average relative concentration of $\mathrm{B}$

303 cells in various organs before and after immunization were different, but the characters of

304 these changes in every organ of Th male and female mice were, to some extent similar 305 (Figs 2 and 3).

306

307 The content of $\mathbf{T}$ cells in different organs of mice

308 The patterns of changes in the number of $\mathrm{T}$ lymphocytes in the bone marrow of Th male

309 and female mice before and after the immunization were directly opposite. We evaluated

310 overtime dependencies in the changes average relative number CD4 and CD8 lymphocytes

311 in various organs before and after mice immunization with MOG. Th male mice before

312 immunization during spontaneous EAE demonstrated during 20 days a slight decrease in

313 the relative number of total CD4 cells in the bone marrow with access to the plateau after

31420 days (Fig. 4a). After immunization, a stronger decrease in the relative number of CD4

315 was observed with its very sharp increase on day $22(P<0.05)$. During the spontaneous

316 development of EAE in Th female mice, the relative number of CD4 cells began to

317 increase only after 40-50 days compared to zero time (Fig. 4a). After immunization of Th 
318 female mice, a smooth but finally very strong decrease in average CD4 lymphocytes in the

319 bone marrow $(P=0.015)$ in comparison with spontaneous EAE was observed (Fig. 4a).

320 During the spontaneous development of EAE, male and female mice demonstrated

321 similar patterns of changes in CD4 cells in the blood with a sharp increase at 7-15 days

322 after the start of the experiment. Immunization of Th male and female mice resulted in a

323 strong decrease in the relative number of CD4 lymphocytes in their blood and complex

324 jump-like patterns of changes in these cells over time (Fig. 4b). The difference in the

325 number of CD4 cells before and after immunization in males was statistically significant $(P$

$326=0.02)$ but not in females $(P=0.09)$. The maximum 4.1 -fold difference $(P<0.05)$ in this

327 parameter in females was observed at 8 days.

328 The patterns of a slow increase in the average relative number of CD4 cells in the

329 thymus of Th female and male mice during spontaneous development of EAE were similar

330 (Fig. 4c). The type of dependencies of CD4 cells changes in the thymus of Th female and

331 male mice were also to some extent resembling a sharp increase at day 23 and the

332 subsequent powerful decrease in the number of lymphocytes at day 40. However, changes

333 in CD4 cells for male and female mice over time were nevertheless very different $(P=$

$3340.003)$.

335 Before immunization of Th male and female mice with MOG, they showed a similar 336 slight overtime decrease in the amount of spleen CD4 lymphocytes (Fig. 4d). The 337 immunization of male mice with MOG led to a slight increase in the number of 338 lymphocytes at 7-15 days with their subsequent decrease (Fig. 4d). In female mice, after 339 immunization with MOG, a very complex change in the number of CD4 lymphocytes was 340 observed with a few weak highs and lows.

341 More unambiguous and similar patterns of changes in the number of CD4 lymphocytes 342 were found in the lymph nodes of Th male and female mice (Fig. 4e). Prior to the 343 immunization, the curves of overtime decrease in the number of CD4 cells in lymph nodes 
344 in female and male mice were comparable. After immunization of Th mice, there was a

345 sharp increase in the number of CD4 cells in these organs of male and female mice from 7

346 to 23 days, and then there was a very strong decrease in their relative number (Fig. 4e). The

347 maximum 1.3 -fold $(P<0.05)$ difference in the number of CD4 cells in female and male

348 mice after immunization was observed at 15 days. During the spontaneous development of

349 EAE, the patterns of changes in CD8 cells in the bone marrow of Th mice are similar (Fig.

350 5a) to overtime changes in CD4 lymphocytes (Fig. 4a).

351 In the first 7-15 days, there is a noticeable decrease in their average relative number

352 for male but an increase for female mice (Fig. 5a). Then the Th male mice demonstrated a

353 plateau, while the female mice show an increase in CD8 cells after 40 days (Fig. 5a).

354 Interestingly, the patterns of overtime changes in the number of CD8 lymphocytes in the

355 bone marrow of Th male and female mice (Fig. 5a) also have a similar character to those

356 for CD4 cells (Fig. 4a). The number of CD8 cells in female mice sharply decreases by day

35720 and reaches a plateau; the strong difference in average data before and after mice

358 immunization during complete experiments is observed $(P=0.003)$. In the case of male

359 mice, there is a strong decrease in the number of these lymphocytes following a sharp

360 splash in their number on day 22 (Fig. 5a). At 22 days, the difference in the number of cells

361 of immunized female and male mice is 12.5 times $(P=0.007)$.

362 The curves characterizing changes in CD8 and CD4 lymphocytes in the blood before

363 immunization of Th male and female mice are, to some extent, similar to a larger or

364 smaller increase in their number in 7 days with the following decrease in their number

365 (Figs 4b and 5b). After immunization of female mice, there is a very slight increase in CD8

366 lymphocytes with a temporary plateau when male mice show a sharp increase in the

367 number of these cells up to day 22 with their subsequent decrease (Fig. 5b). A maximal 2-

368 fold difference $(P<0.05)$ in the number of CD8 cells in immunized female and male mice

369 is observed 22 days after their treatment. 
The characters of the in-time changes in CD8 cells in the thymus of Th male and

371 female mice before immunization is somewhat close to that for these lymphocytes changes

372 in the bone marrow (Fig. 5c) and CD4 cells in the thymus (Fig. 4c). The curve corresponding to overtime changes in CD8 in the thymus of male mice (Fig. 5c) after their immunization almost repeats that for the bone marrow (Fig 5a). At the same time, the patterns of changes in CD8 lymphocytes in the thymus and bone marrow of female mice treated with MOG are very different (Figs 5a and 5c). In contrast to the continuous

377 decrease in time of the number of these cells in the bone marrow of immunized female mice, a sharp increase in their content from 15 to 22 days is observed in the thymus (Fig. 5c). Interestingly, the patterns of changes in the number of CD8 cells in the thymus in female and male mice before and after their immunization are very similar (Fig. 5c).

The time-dependent curves of the number of CD8 lymphocytes during the spontaneous development of EAE in the spleen of Th male and female mice are different (Fig. 5d). Female mice show a constant decrease in these lymphocytes, reaching a plateau at about day 40. In male mice, there is a remarkable increase in the number of CD8 cells up to 15-20 days with their subsequent decrease. Immunization of Th male mice leads in the spleen to a sharp decrease in the number of CD8 cells with a noticeable increase in 30 days (Fig. 5d). The characters of the changes in time of the relative number of CD8 (Fig. 5d) as well as CD4 (Fig. 4d) in the spleen of female mice are very complex. In both cases, there is a temporary increase in the relative number of CD8 and CD4 cells at $\sim 30$ and 60 days. male and female mice, both before and after their immunization with MOG (Fig. 5e).

392 During the spontaneous development of EAE, male and female mice in overall show an 393 almost smooth increase in the number of these cells over time. After immunization of male 394 and female mice, there is a sharp increase in the relative number of CD8 lymphocytes to 395 day 22 with their subsequent decrease (Fig. 5e). 
397 female mice are very complex. The greatest differences in the number of CD4 and CD8

398 cells are observed in the bone marrow of male and female mice after their immunization with MOG (Figs 4a and 5a). In addition, there was observed a significant difference in the dependencies of overtime changes in CD8 cells in male and female mice after their immunization with MOG (Fig. 5b). The most complex and unlike other organs character of changes in CD4 and CD8 lymphocytes was found in the spleen of female mice (Figs 4d and 5d). usually occurs at 17-20 days after the immunization and after 30-40 days begins remission stage [29-32]. Interestingly, after immunization with MOG in nearly all organs of Th male and less often in female mice similar to C57BL/6 mice; there was a sharp increase in the relative average number of CD4 and CD8 lymphocytes in the period from 7 to 23 days corresponding to the onset and acute stage (Figs 4 and 5). In the period corresponding to the mouse remission stage (after 30-40 days), depending on the organ, there might be a remarkable decrease or an increase in the relative number of CD4 and CD8 lymphocytes.

\section{The relative content of antibodies against proteins and DNA}

415 The blood of different healthy mammals usually contains autoantibodies against DNA, 416 RNA, and various proteins in low concentration [13-17]. The concentrations of auto-Abs to 417 DNA in blood sera of non-autoimmune BALB and CBA mice (at 3-15 months of age) as 418 well as healthy MRL-lpr/lpr mice (at 2-3 months of age) are low; $0.03-0.04 \mathrm{~A}_{450}$ units [9-

419 11]. In sera of EAE prone C57BL/6 mice, the concentrations of anti-DNA Abs are higher ( 0.11 $\mathrm{A}_{450}$ units), and during spontaneous development of pathology, it increased slowly 
days of spontaneous development of EAE, the anti-DNA Abs concentration in Th mice

423 increased 5.3- and 3.8-fold $(P<0.05)$ for female and male mice, respectively (Fig. 6a).

424 The treatment of Th mice with MOG led to a significant and comparable decrease in antiDNA Abs concentration in sera of male and female mice during the onset and acute phase (7-23 days) of EAE (at 14 days 3.6-4.0-fold, $P<0.05$ ) (Fig. 6a). However, then, during the

427 period of remission (> 30 days), the concentration of anti-DNA antibodies was slowly 428 increased; the difference in the concentration of anti-DNA Abs before and after 429 immunization of mice with MOG during the entire analysis period was statistically 430 significant, $P<0.05$.

Interestingly, unlike Th mice, immunization with MOG of C57BL/6 male mice did not lead not to the decrease but to an increase in the concentration of anti-DNA in the blood sera (Supplementary Fig. S3).

434 We evaluated the changes over time in the concentration of Abs against MBP and MOG using homogeneous preparations of polyclonal IgGs isolated from the sera of male and female mice. The relative concentration of anti-MBP during 73 days of spontaneous development of EAE increased 2.3-fold in females and 1.8-fold in male mice $(P<0.05)$.

438 As in the case of anti-DNA auto-Abs, immunization of male and female mice with MOG 439 led to a sharp decrease in the concentration of antibodies against MBP starting the first 440 seven days after mice immunization (at 7 days 1.6-2.0-fold, $P<0.05$ ) (Fig. 6b). Wherein, 441 after immunization, a statistically significant difference was observed between the anti442 MBP IgGs concentrations in female and male mice $(P=0.02)$.

443 As shown earlier, the blood of C57BL/6 mice, even at 3 months of age, contains Abs 444 against MBP, and their concentrations increase during spontaneous but much faster after 445 male immunization with MOG (Supplementary Fig. S3) [7,8,34,35]. During the 446 spontaneous development of EAE in Th male and female mice, auto-Abs against MOG 447 increased almost linearly from 0.02 to $0.032-0.036 \mathrm{~A}_{450}, P<0.05$ (Fig. 6c). It was 
reasonable to expect that immunization of mice with external MOG will lead to a sharp

449 increase in the concentration of antibodies against this peptide. However, we obtained an unexpected result. The immunization of mice with MOG peptide led to a very powerful suppression of the formation of antibodies against this peptide (from 7 to 40 days) in both male and female mice (Fig. 6c) with the statistically significant difference before and after mice treatment, $P=0.005$ and 0.01 , respectively. During spontaneous development of EAE in C57BL/6 male mice, as well as in Th male mice, a gradual, almost linear increase in the concentration of antibodies against MOG was observed. After C57BL/6 male mice immunization in contrast to Th mice, there was observed a higher increase of anti-MOG Abs in comparison with spontaneous development of EAE (Supplementary Fig. S3).

Thus, in contrast to non-autoimmune mice, the concentration of antibodies against DNA, MBP, and MOG increases during spontaneous development of EAE over time in Th

460 male and female mice, as is the case for other animals predisposed to develop spontaneous autoimmune diseases $[7,8,34,35]$. The main difference in the production of auto-Abs in autoimmune prone Th and C57BL/6 mice is that immunization with MOG leads to a sharp decrease in the concentration of Abs against DNA, MBP, and MOG in Th mice, while there is a sharp increase in their concentration at the onset and acute phase of the disease in C57BL/6 mice.

\section{Criteria analysis of catalytic activities of antibodies}

Previously, it has been demonstrated that in contrast to non-autoimmune mice (BALB and CBA), IgG antibodies from the blood of EAE prone C57BL/6 mice $[7,8,34,35]$ already at the age of 3 months possess the catalytic activity, and they are able to hydrolyze DNA, MBP, and MOG. The level of catalytic activity of IgG-abzymes of C57BL/6 mice in the hydrolysis of these substrates is continuously increasing during spontaneous and, to a

473 greater extent, after MOG-induced development of EAE [7,8,34,35]. To obtain 
electrophoretically homogeneous IgG preparations deprived of impurities of any classical enzymes, we have developed a universal technique. It includes affinity chromatography on Protein G-Sepharose of sera proteins in conditions removing nonspecifically bound components $[7,8,34,35]$. The purified IgGs are then additionally subjected to FPLC gel filtration in an acidic buffer $(\mathrm{pH}=2.6)$. The homogeneity of IgGs was shown in this article (Fig. 7a) as in all previous publications by SDS-PAGE with silver staining [7,8,34,35].

$$
\text { To show that DNA- and different proteins-hydrolyzing activities are the own properties }
$$
of antibodies, and they do not contain co-purified canonical enzymes, we used several known very strict criteria $[7,8,34,35]$. It was shown that IgGs from sera of Th mice obtained using the described approach do not contain impurities of any canonical DNases and proteases. A more detailed description of the method of IgGs antibodies purification from sera of mice and data on the analysis of the affiliation of enzymatic activities directly to antibodies are given in Supplementary Methods (part 2: "IgG purification"). To prove the belongings of enzymatic activities to Th mice antibodies, a mixture of IgGs was used for the analysis of catalytic activities (Fig. 7b). After IgGs SDS-PAGE (part 3 "SDS-PAGE analysis of catalytic activities"), it was shown that Th mice antibodies do not contain any impurities of canonical enzymes, and they may be used to evaluate their relative activity in the hydrolysis of DNA and proteins.

\section{Time-dependent changes in IgGs catalytic activities}

It has been shown that abzymes that hydrolyze DNA and proteins are absent in the blood of non-autoimmune BALB and CBA mice. The appearance of abzymes possessing various enzymatic activities is shown as a very important marker of onset and development for various AIDs [7-11,34,35]. Healthy humans do not usually demonstrate catalytic activities of Abs [13-17]. The blood sera of SLE-prone MRL-lpr/lpr male and female mice contain Abs-abzymes possessing DNA-, ATP-, and oligosaccharides-hydrolyzing activities 
501 in DNase activity during spontaneous development of this pathology.

502 At time zero, DNA-hydrolyzing activity of IgGs in Th female mice was approximately by a factor of 2.5 higher than that for male mice $(P<0.05)$ (Fig. 8 a).

505 female mice Abs was increased 2.8-fold, while for male mice, IgGs activity was risen by a 506 factor of $11(P<0.05)$ (Fig. 8a). The immunization with MOG of male mice led to an 507 increase in this activity today 30 by a factor of 32 , while for female mice 11 -fold, $P<0.05$ 508 (Fig. 8a). The DNase activity of female antibodies at 83 days after immunization was 2 509 times higher than that from the blood of males $(P<0.05)$. Approximately the same 510 situation was found earlier for C57BL/6 male mice; immunization with MOG led to an 511 increase in activity 25-fold at about day 20 after immunization of mice (Supplementary 512 Fig. S4). It should be noted that immunization of C57BL/6 male mice leads to a strong increase in the concentration of anti-DNA antibodies and to a parallel increase in their activity in DNA hydrolysis. At the same time, at a sharp decrease in the concentration of antibodies against DNA in Th mice (Fig. 6a), there is a very strong increase in their activity 516 in the splitting of DNA (Fig. 8a).

517 The relative activity of IgGs from Th male and female mice at zero time in the hydrolysis of MBP was nearly the same (Fig. 8b). There was, however, a strong slowdown

519 in the growth of abzyme MBP-hydrolyzing activity in sera of males compared to females 520 during the spontaneous development of EAE (Fig. 8b). In male mice after immunization, 521 there was a sharp increase in the hydrolysis of MBP antibodies at 7 days. But then, after 20 522 days, there was a decrease in MBP-hydrolyzing activity in male and female mice (Fig. 8b). 523 Finally, at 73 days after immunization, the activity of antibodies from the serum of male 524 and female mice was 23-26 times lower than before their treatment with MOG after 525 spontaneous development of $\operatorname{EAE}(P<0.05)$. 
The profiles of changes in the activity of antibodies from the blood of female and male

527 mice in the hydrolysis of MOG before as well as after immunization of mice are very

528 similar (Fig. 8b). The increase over time in the relative concentrations of Abs against MBP

529 in male and female mice during spontaneous development of EAE correlates with the

530 increase in the activity of abzymes hydrolyzing MBP (Figs $6 \mathrm{~b}$ and $8 \mathrm{~b}$ ). At the same time, a

531 keen decrease in the concentration of antibodies against MOG (Fig. 6c) after the

532 immunization was inversely related to the significant increase in the relative activity of

533 these antibodies in the hydrolysis of MOG (Fig. 8c).

534 Before and after immunization of C57BL/6 male mice, there were parallel increases in 535 the concentration of anti-MOG antibodies and their activities in MOG hydrolysis 536 (Supplementary Figs S3 and S4).

537 Thus, some noticeable differences are apparent for male and female mice, not only in 538 the dependencies of changes over time in differentiation profiles of stem cells (Fig. 1) and 539 patterns of changes in lymphocyte proliferation in different organs (Figs 2-4), but also in 540 relative concentrations of Abs against DNA, MBP, and MOG, as well as IgG activities in 541 their hydrolysis (Figs 6 and 8).

\section{Discussion}

544 The spontaneous achievement of SLE in MRL-lpr/lpr and EAE in C57BL/6 mice is significantly accelerated by mice treatment with DNA and MOG, respectively. The development of SLE in MRL-lpr/lpr and EAE in C57BL/6 mice are characterized by very

547 similar changes in the HSCs differentiation profile and the beginning of the production of 548 different abzymes at the onset and acute phases of EAE and SLE [7-11,34,35].

549 The activated myelin-reactive B and T cells are both important for MS pathogenesis in 550 mammals [1-3]. Therefore, it was interesting to analyze the changes of pathology 
development important parameters during the spontaneous and MOG-accelerated

552 development of EAE in Th mice, demonstrating a T lymphocyte response [33].

553 The main difference in the differentiation profiles of HSCs during spontaneous 554 development of EAE in Th male and female mice was revealed for CFU-E, CFU-GEMM, and T cells. However, the differentiation of BFU-E, CFU-GM, and B cells was, to some extent, similar (Fig. 2). After mice immunization with MOG, a certain similarity in the differentiation was observed for BFU-E, CFU-E, CFU-GEMM, and B-cells, but it was reverse directions for CFU-GM colonies and T cells (Fig. 2). Some differentiation profiles of HSCs in male C57BL/6 mice (Supplementary Fig. S2) in overall were different in comparison with Th mice (Fig. 2).

After immunization of mice with MOG in nearly all organs of Th male and female mice similar to C57BL/6 mice, was observed a sharp increase in the relative number of

563 lymphocytes in the period from 7 to 23 days corresponding to the onset and acute stages of pathology (Figs 4 and 5).

Despite the differences between male and female mice in profiles of HSCs differentiation and lymphocyte proliferation in various organs, in both cases, these

567 processes lead to the production of auto-Abs against DNA, MBP, and MOG, including 568 abzymes hydrolyzing these substrates (Figs 6 and 8). Many parameters characterizing the development of EAE in C57BL/6 mice (Supplementary Figs S1-S4) are significantly different in comparison with Th mice. Interestingly, in the case of C57BL/6 mice, there is

571 some correlation between the growth of antibody concentrations against DNA, MOG, and 572 MBP, and the parallel increase in the efficiency of these substrates hydrolysis up to about 573 20-30 days (Supplementary Figs S3 and S4). At the same time, several dependencies showing changes in concentrations of antibodies against DNA, MBP, and MOG in Th mice do not correlate with those characterizing hydrolysis of these substrates (compare Figs 6 and 8). It was shown that due to the extreme diversity of abzymes hydrolyzing different 
antigens, specific stages of AIDs development might be characterized by the production of

578 various auto-Abs without and with low or high catalytic activities [11-17]. It is reasonable

579 to suggest, therefore, that after immunization of Th mice with MOG, a parallel decrease in

580 the concentration of the auto-Abs without catalytic activity takes the increase in the

581 concentration of abzymes hydrolyzing these antigens.

582 It should be assumed that significant differences in immunoregulation in women and

583 in men can occur not only at the level of stem cell differentiation and production of

584 abzymes but also in the expression of immune-related microRNAs. For example, it was

585 shown that in patients with multiple sclerosis, miR-379-5p and miR-223-3p were

586 upregulated only in men [41,42]. Increased expression of miR-127-3p, miR-431, miR-379,

587 miR-381, miR-376c, miR-656, and miR-410 has also been revealed only in males but not

588 in female analyzed patients with relapsing-remitting multiple sclerosis [41,42]. It cannot be

589 ruled out that the development of MS in men and women may differ with respect to

590 different changes in any other parameters.

591

592

593 Methods

594 Chemicals

595 Protein G-Sepharose and Superdex 200 HR 10/30 columns were obtained from GE

596 Healthcare (New York, USA), bovine polymeric DNA, and other different proteins and

597 chemicals were from Sigma-Aldrich (Munich, Germany). 18.5 kDa human MBP was from

598 the Research Center of Molecular Diagnostics and Therapy (RCMDT, Moscow, Russia),

599 and mouse oligopeptide $\mathrm{MOG}_{35-55}$ was perched from EZBiolab (Germany). All

600 preparations were free from any possible contaminants. Methylcellulose-based M3434

601 medium was from StemCell Technologies (Canada) and RBC lysis buffer from Biolegend

602 (San Diego, CA, USA). Fetal bovine serum was from Invitrogen (Waltham, MA, USA) 


\section{Experimental animals}

605 Th mice line with T-cell response was matured in Germany (Westfälische Wilhelms-

606 Universität, Department of Neurology, Münster). The main characteristics of this line of

607 mice, they are predisposed to the development of EAE, are described in [33].

608 Inbred Th mice (3 months of age at the beginning of all experiments) were grown in the

609 Institute of Cytology and Genetics (ICG) special mouse breeding facility in standard

610 conditions free of any pathogens. All experiments were carried out with mice pursuant to

611 protocols of the Bioethical Committee of the Institute of Cytology and Genetics (document

612 number 134A of 07 September 2010), satisfying the humane principles of the European

613 Communities Council Directive (86/609/CEE) for working with animals. The Bioethical

614 Committee of ICG supported this study. The relative overtime weight of male and female

615 mice and degree of proteinuria (concentration of total protein in the urine, $\mathrm{mg} / \mathrm{ml}$ ) were

616 analyzed as in [9-11]. For comparison, we used C57BL/6 wild-type mice described earlier

$617[7,8,31]$.

618

619 Immunization of mice

620 Analysis of changes in various parameters, characterizing the development of EAE during 70-83 days, was carried out in the case of groups of seven female and male mice without any treatment and after their immunization with MOG. Immunization (or treatment) of Th mice with $\mathrm{MOG}_{35-55}$ was performed using $\mathrm{MOG}_{35-55}$ and Pertussis toxin according to a

624 previously published protocol [31] used previously in [7]. On day 1 (zero time of experiments), Th mice were treated by injection of $30 \mu \mathrm{g}$ of $\mathrm{MOG}_{35-55}$ per mouse in the

626 back, two times in the left and right side using $20 \mu \mathrm{l}$ of Freund's complete adjuvant 627 containing Pertussis toxin (400 ng/mouse; Mycobacterium tuberculosis). The next day 20 $628 \mu \mathrm{l}$ of Pertussis Toxin (400 ng / mouse) was additionally injected in a similar way. For 
different experiments, $0.7-1 \mathrm{ml}$ of the blood was collected after decapitation using standard

630 approaches.

631

\section{ELISA of anti-proteins and anti-DNA antibodies}

633 Anti-DNA Abs analysis (the sera were diluted 100-fold) was performed using the ELISA

634 test system of ORGENTEC Diagnostika (Germany) according to the manufacturer's 635 instructions as in [7-9,34,35]. The relative contents of IgGs against $\mathrm{MBP}$ and $\mathrm{MOG}_{35-55}$ 636 were estimated using purified polyclonal electrophoretically homogeneous Abs as in [7$6379,34,35]$. After all previously described stages of the treatment of immobilized MBP and 638 MOG and bound with them IgGs, rabbit anti-mouse Abs conjugated with horseradish 639 peroxidase were added; all samples were incubated with $\mathrm{H}_{2} \mathrm{O}_{2}$ and then with 640 tetramethylbenzidine. The optical densities of the solutions $\left(\mathrm{A}_{450}\right.$; after adding $\left.\mathrm{H}_{2} \mathrm{SO}_{4}\right)$ 641 were measured using the Uniskan II plate reader (MTX Lab Systems, USA) [7-9]. The 642 relative $A_{450}$ values of the samples were calculated from differences in $A_{450}$ between 643 experimental and control solutions containing no DNA, MBP, or MOG. More detailed data 644 concerning the determination of anti-DNA and anti-proteins concentrations are given in 645 Supplementary data (Part 1: "ELISA of anti-proteins and anti-DNA antibodies")

647 IgG purification

648 Electrophoretically homogeneous IgGs from blood sera of Th mice were obtained using affinity 649 chromatography of sera components on Protein G-Sepharose and following FPLC gel filtration of 650 IgGs in drastic conditions ( $\mathrm{pH} 2.6)$, destroying immunocomplexes as in [7,8,21-23,34,35]. More 651 detailed data concerning these methods are given in Supplementary data (Part 2: "IgG purification"). IgGs were protected from viral and bacterial contamination by their filtration using 653 Millex membranes $(0.1 \mu \mathrm{m})$. Analysis of IgGs by SDS-PAGE was carried out using gradient gels $654(4-15 \%)$ and visualized using silver staining according to [7,8,21-23,34,35]. 
DNA-hydrolyzing activity assay

657 DNase activity of IgGs was estimated according to [9,24,25]. The mixtures (20 $\mu \mathrm{L})$ containing 20 mM Tris- $\mathrm{HCl}(\mathrm{pH} 7.5)$ supplemented with $20 \mathrm{mM} \mathrm{NaCl}, 1 \mathrm{mM}$ ethylenediaminetetraacetic acid (EDTA), $5 \mathrm{mM} \mathrm{MgCl} 2,20 \mu \mathrm{g} / \mathrm{ml}$ supercoiled (sc) pBluescript, and 0.001-0.1 mg/ml of IgGs. The samples were incubated during 5-24 h at $37^{\circ} \mathrm{C}$. The products of DNA splitting were analyzed using $0.8 \%$ agarose gels electrophoresis. Photographs of ethidium bromide-colored gels were analyzed by Gel-Pro Analyzer v9.11 (Media Cybernetics, L.P., Germany). The relative catalytic activities (RAs) were calculated from the difference between the relative amount of intact supercoiled DNA (scDNA) and its hydrolyzed-relaxed form, taking into account DNA-substrate distribution between these two bands after scDNA incubation without IgGs. All initial DNA splitting rates were analyzed from linear parts of the reaction time dependencies (30-40\% of scDNA hydrolysis) and concentrations of Abs providing 30-40\% of scDNA hydrolysis. A complete transition of scDNA to its relaxed form was taken for $100 \%$ of the activity. The relative activities ( $\%$ of the hydrolysis) were finally recalculated to the same standard conditions; time and IgGs concentration (mole of sc DNA / min/mg of IgGs).

\section{Protease activity assay}

673 The mixtures $(10-50 \mu \mathrm{L})$ containing $20 \mathrm{mM}$ Tris- $\mathrm{HCl}$ buffer $(\mathrm{pH} 7.5)$ supplemented with $0.7-1.0$ $674 \mathrm{mg} / \mathrm{ml}$ of proteins (MBP or MOG), as well as $0.001-0.2 \mathrm{mg} / \mathrm{mL}$ of IgGs were incubated for 5-24 h at $37^{\circ} \mathrm{C}[7,8,21-23,34,35]$. The proteins cleavage products were estimated by SDS-PAGE using $12 \%$ or $3-15 \%$ gradient gels with the following staining Coomassie R250. The gels were scanned, and hydrolyzed products were quantified by GelPro v3.1 software. IgG samples' relative activities were evaluated from a decrease (\%) in the initial MOG or MBP transited to their hydrolyzed forms.

679 The hydrolysis of the proteins incubated without antibodies was taken into account. All initial hydrolysis rates were calculated using pseudo-first-order reaction conditions, linear regions of 
681

682

683

684

685

686

687

688

689

690

691

692

693

694

695

696

697

698

699

700

701

702

705

706

703 Evaluation of lymphocytes in different mouse tissue samples

704 The relative content of $\mathrm{B}$ and $\mathrm{T}$ lymphocytes in various organs and blood of mice was

reactions time dependencies, and IgGs concentrations (20-40\% hydrolysis of the proteins). The relative activities (\% of the hydrolysis) were finally recalculated to the same standard conditions; time and IgGs concentration (mole of protein (MBP or MOG) / min/mg of IgGs).

\section{SDS-PAGE analysis of catalytic activities}

To prove that antibody activity is their own property, the analysis of DNA- and different proteins-hydrolyzing activities of Th mice IgGs after SDS-PAGE was performed as in [7,8,21-23,34,35]. These methods have been developed and published previously and are given in Supplementary data (Part 3: "SDS-PAGE analysis of catalytic activities").

\section{Analysis of bone marrow progenitor cells in culture}

Samples of bone marrow were obtained from 14 mouse femurs, and then the ability of bone marrow cells to form different colonies was estimated as in $[7,8,34,35]$. The standard methylcellulose-based M3434 medium specific for mouse cells was used; four dishes per mouse $\left(2 \times 10^{4}\right.$ cells) were grown. The medium contained erythropoietin (EPO), stem cell factor, and interleukins IL-3 and IL-6. The relative number of CFU-GM (granulocytemacrophage colony-forming unit), CFU-GEMM (granulocyte-erythroid-megakaryocytemacrophage colony-forming unit), BFU-E (erythroid burst-forming unit, early erythroid forming unit), and CFU-E (erythroid burst-forming unit, late erythroid forming unit) cell colonies on the dishes was calculated after 14 days of incubation at $37^{\circ} \mathrm{C}\left(5 \% \mathrm{CO}_{2}\right)$ in a humidified incubator as in [7,8,34,35]. estimated by flow cytometry. Peripheral blood was obtained using mice's standard decapitation. Sodium citrate was used as an anticoagulant. Five hundred thousand 
707 leukocytes in not more than $150 \mu \mathrm{L}$ were used for cytometric analysis. Cells were

708 incubated with monoclonal Abs for 20 min in the darkness, then the cells of blood samples

709

710

711

712

713

714

715

716

717

718

719

720

721

722

723

724

725

726

727

728

729

730

731

732 were lysed using a special 10-fold volume of RBC lysis buffer for $20 \mathrm{~min}$, centrifuged for $10 \mathrm{~min}$, and washed using $500 \mu \mathrm{L}$ of PBS buffer $\left(150 \mathrm{mM} \mathrm{NaCl}, 17 \mathrm{mM} \mathrm{KH} \mathrm{PO}_{4}, 52 \mathrm{mM}\right.$ $\mathrm{Na}_{2} \mathrm{HPO}_{4}$ ) containing $0.02 \%$ EDTA and $1 \%$ sodium azide. After samples centrifugation, 50 $\mu \mathrm{L}$ of PBS buffer was added to the cell pellet, and they were analyzed by a flow cytometer. Lymphocytes were isolated from blood, bone marrow, thymus, lymph nodes, and spleen. Bone marrow was derived by rinsing the femoral cavity. Lymph nodes and thymus samples were carefully homogenized, large particles were removed, and different cells were resuspended by their passing using a disposable syringe through a needle. Spleen cells were received by washing this organ with a medium-filled syringe through punctures in the spleen stroma. This approach allows the obtaining of splenocytes without impurities from the stroma of the spleen. Cells were then washed by their centrifugation with RPMI1640 medium $(5 \mathrm{ml})$ at $1500 \mathrm{rpm}$ for $10 \mathrm{~min}$. After the second centrifugation, RPMI-1640 medium (1 ml) containing $10 \mathrm{mM}$ HEPES, $10 \%$ fetal bovine serum, $0.5 \mathrm{mM} 2-$ mercaptoethanol, $2 \mathrm{mM}$ L-glutamine, $100 \mu \mathrm{g} / \mathrm{ml}$ benzylpenicillin, and $80 \mu \mathrm{g} / \mathrm{ml}$ gentamicin were added to the cell pellets, and the cells were counted. The relative cell content in extracts of various organs was analyzed using 500 thousand cells in $100 \mu \mathrm{L}$ of PBS buffer supplemented with $10 \%$ fetal bovine serum and the conjugates of different specific monoclonal antibodies. To analyze the relative amount of different cells, specific antiCD45-BV510 (Biolegendcat \# 103138), antiCD3-FITC (Biolegendcat \# 100204), antiCD4-PerCP (Biolegendcat \# 100432), antiCD8alpha-APC (Biolegendcat \# 126614), and antiCD19-PE (Biolegendcat \# 115508) antibodies were used. All staining of cells was carried out according to the manufacturer's recommendations. Cells were incubated for 20 min with monoclonal antibodies, washed by centrifugation after adding $500 \mu \mathrm{L}$ of PBS. 50 $\mu \mathrm{L}$ of PBS after centrifugation was added to the cell pellet, and the mixtures were used for 
analysis using the BD FacsVerse flow cytometer (BD Biosciences, SanJose, CA, USA).

734 More than 100,000 events were collected for each sample. Gating was performed as

735 follows: the total cell population was isolated according to cell size and granularity, and the white blood cell population was determined using the pan-white blood cell marker CD45+ and populations of $\mathrm{CD} 3+$ and $\mathrm{CD} 3$-leukocytes were obtained. In the CD3+ leukocytes population ( $\mathrm{T}$ cells), CD4+ and CD8+T cells were determined, and in the CD3- leukocytes population, the relative content of CD19+ B cells was found. For all groups, the percentage ratio was calculated relative to the initial lymphocyte population.

\section{Statistical analysis}

743 The final determined values are given as the mean \pm S.D. of three independent experiments for each

744 mouse (7 male and 7 female mice); the data were averaged over seven different male and female

745 mice of each group. Some of the sets of samples did not match the Gaussian distribution. Therefore,

746 to estimate the differences between parameters analyzed, the Mann-Whitney U test was utilized; $P<$

$747 \quad 0.05$ was regarded statistically significant.

\section{Conclusion}

750 Here, the analysis of several important specific parameters characterizing spontaneous and MOG-induced development of EAE in Th mice with a T lymphocytes response and their comparison with those for C57BL/6 mice with T- and B-response was carried out for the first time. Despite the fact that the significant differences in the studied parameters in Th and C57BL/6 mice, the development of EAE, in both cases, is associated with a change in the bone marrow stem cell differentiation profile, an increase in the proliferation of lymphocytes in various organs, and the production of catalytic antibodies that are harmful to mice. 
760 Abbreviations used: Abs, antibodies; auto-Abs, autoantibodies; AI, autoimmune; AIDs,

761

762

763

764

765

766

767

768

769

770

771

772

773

774

775

776

777

778

779

780

781

782

783

784

785

autoimmune diseases; BFU-E, erythroid burst-forming unit (early erythroid colonies); CFU-GM, granulocyte-macrophage colony-forming unit; CFU-E, erythroid burst-forming unit (late erythroid colonies); CBA, (CBAxC57BL)F1 mice; CFU-GEMM, granulocyte-erythroid-megakaryocytemacrophage colony-forming unit; cerebrospinal fluid; CNS, central nervous system; CSF, EPO, erythropoietin; EAE, experimental autoimmune encephalomyelitis; EPO, HSCs, hematopoietic stem cells; IgG, immunoglobulin G; IL, interleukin; MBP, myelin basic protein; $\mathrm{MOG}_{35-55}$, myelin oligodendrocyte glycoprotein; MTT, tetrazolium dye MTT 3-(4,5-methylthiazol-2-yl)-2,5diphenyltetrazolium bromide; MS, multiple sclerosis; SDS-PAGE, sodium dodecyl sulfatepolyacrylamide gel electrophoresis; sc, supercoiled; scDNA, supercoiled DNA; SLE, systemic lupus erythematosus.

Author Contributions: conceptualization, I.A.O. and G.A.N. ; methodology, I.A.O., N.A.P., and G.A.N. ; formal analysis, T.B., S.G.M., and G.A.N; investigation, K.S.A. S.E.S., A.E.U., L.B.T., Y.A.S., V.P.T., N.A.P; resources, G.A.N., T.B., S.G.M. and S.V.S.; data curation, G.A.N., and I.A.O; writing — original draft preparation G.A.N. and I.A.O; writing—review and editing, T.B., S.G.M.and G.A.N.; project administration, G.A.N.; funding acquisition, G.A.N. T.B., S.G.M., and S.V.S.

Funding: This work was granted-supported by the Russian Science Foundation (Number 19-1500145); Bundesministerium für Bildung und Forschung (BMBF), Grant/Award Number:

01DJ12103;DFG, Grant/Award Number: CRC128-B06.

Supplementary Materials: They are available online at ??

\section{Declarations}

\section{Ethics approval and consent to participate}


All experiments were carried out with mice pursuant to protocols of the Bioethical Committee of the

787 Institute of Cytology and Genetics (document number 134A of 07 September 2010), satisfying the humane principles of the European Communities Council Directive (86/609/CEE) for working with animals.

\section{Consent for publication}

791

792 All authors have analyzed the manuscript and agree with its submission.

\section{Competing interests}

794 The authors declare absence conflicts of interest.

795 Author details

$796{ }^{1}$ Institute of Chemical Biology and Fundamental Medicine, Siberian Branch of the Russian 797 Academy of Sciences, Novosibirsk, Russia;

798 Institute of Clinical Immunology, Siberian Branch of the Russian Academy of Sciences, 799 Novosibirsk, Russia;

$800{ }^{3}$ Westfälische Wilhelms-Universität, Institut für Physiologie I, Robert-Koch-Str. 27a, D-

80148149 Münster, Germany

$802{ }^{4}$ Klinik für Neurologie Universitätsklinikum Düsseldorf, Moorenstraße 5, Germany.

803

804

\section{References}

806 1. O’Connor, KC, Bar-Or A, Hafler DA. The neuroimmunology of multiple sclerosis: Possible roles

807 of T and B lymphocytes in immunopathogenesis. J Clin Immunol. 2001;21:81-92.

808 2. Archelos JJ, Storch, MK, Hartung HP, The role of B cells and autoantibodies in multiple 809 sclerosis, Ann Neurol. 2000;47:694-706

810 3. Hemmer B, Archelos JJ, Hartung HP. New concepts in the immunopathogenesis of multiple 811 sclerosis. Nat Rev Neurosci. 2002;3:291-301.

812 4. Niehaus A, Shi J, Grzenkowski M, et al. Patients with active relapsing-remitting 813 multiple sclerosis synthesize antibodies recognizing oligodendrocyte progenitor cell 814 surface protein: implications for remyelination. Ann Neurol. 2000;48:362-71. 
815 5. Cross AH, Trotter JL, Lyons J. B cells and antibodies in CNS demyelinating disease.

816 J Neuroimmunol. 2001;112:1-14.

817 6. Ikehara S, Kawamura M, Takao F. Organ-specific and systemic autoimmune diseases 818 originate from defects in hematopoietic stem cells. Proc Natl Acad Sci USA. $819 \quad 1990 ; 87: 8341-4$

820 7. Doronin VB, Parkhomenko TA, Korablev A, Toporkova LB, Lopatnikova JA, Alshevskaja 821 AA, Sennikov SV, Buneva VN, Budde T, Meuth SG, et al. Changes in different parameters, 822 lymphocyte proliferation and hematopoietic progenitor colony formation in EAE mice treated with 823 myelin oligodendrocyte glycoprotein. J Cell Mol Med. 2016;20:81-94.

824 8. Aulova KS, Toporkova LB, Lopatnikova JA, Alshevskaya AA, Sennikov SV, Buneva VN,

825 Budde $\mathrm{T}$, Meuth, SG, et al. Changes in haematopoietic progenitor colony differentiation and 826 proliferation and the production of different abzymes in EAE mice treated with DNA. J Cell Mol 827 Med. 2017;21:3795-3809.

828 9. Andryushkova AS, Kuznetsova IA, Buneva VN, et al. Formation of different abzymes 829 in autoimmune-prone MRL-lpr/lpr mice is associated with changes in colony formation 830 of haematopoetic progenitors. J Cell Mol Med. 2007;11:531-51.

831 10. Andryushkova AA, Kuznetsova IA, Orlovskaya IA, et al. Antibodies with amylase 832 activity from the sera of autoimmune-prone MRL/MpJ-lpr mice FEBS Lett. $833 \quad 2006 ; 580: 5089-5095$.

834 11. Andryushkova AS, Kuznetsova IA, Orlovskaya IA, et al. Nucleotide- hydrolyzing 835 antibodies from the sera of autoimmune-prone MRL-lpr/lpr mice. Int immunol. $836 \quad 2009 ; 21: 935-945$.

837 12. Catalytic antibodies, Keinan E editor, Weinheim, Germany; Wiley-VCH Verlag $838 \mathrm{GmbH}$ and Co KgaA; 2005, p. 1-586.

839 13. Nevinsky GA. Autoimmune processes in multiple sclerosis: Production of harmful 840 catalytic antibodies associated with significant changes in the hematopoietic stem cell 
841 differentiation and proliferation. In: Conzalez-Quevedo A, editor. Multiple sclerosis.

842 Rijeka, Croatia: InTech; 2016, p. 100-147.

843 14. Nevinsky GA, Buneva VN. Natural catalytic antibodies-abzymes. In; Keinan E, 844 editor. Catalytic antibodies. Weinheim, Germany: VCH-Wiley Press; 2005, p. 505-569.

845 15. Nevinsky GA. Natural catalytic antibodies in norm and in autoimmune diseases. In:

846 Brenner KJ, editor. Autoimmune Diseases: Symptoms, Diagnosis and Treatment. New

847 York, NY, USA: Nova Science Publishers Inc; 2010, p 1-107.

848 16. Nevinsky GA. Natural catalytic antibodies in norm and in HIV-infected patients. In:

849 Kasenga FH, editor. Understanding HIV/AIDS Management and Care-Pandemic

850 Approaches the 21st Century. Rijeka, Croatia: InTech; 2011, p. 151-192.

851 17. Nevinsky GA. Catalytic antibodies in norm and systemic lupus erythematosus. In:

852 Khan, WA, editor. Lupus. Rijeka, Croatia: InTech; 2017, p. 41-101.

853 18. Bezuglova AV, Konenkova LP, Doronin BM, Buneva VN, Nevinsky GA. Affinity 854 and catalytic heterogeneity and metal-dependence of polyclonal myelin basic protein855 hydrolyzing IgGs from sera of patients with systemic lupus erythematosus. J Mol 856 Recognit. 2011;24:960-974.

857 19. Bezuglova AM, Konenkova LP, Buneva VN, Nevinsky GA. IgGs containing light 858 chains of the $\lambda$-and $\kappa$-type and of all subclasses (IgG1-IgG4) from the sera of patients with 859 systemic lupus erythematosus hydrolyze myelin. Int Immunol. 2012;24:759-770.

860 20. Andrievskaya OA, Buneva VN, Baranovskii AG, et al. Catalytic diversity of 861 polyclonal RNA-hydrolyzing IgG antibodies from the sera of patients with systemic lupus 862 erythematosus. Immunol Lett. 2002;81:191-198.

863 21. Polosukhina DI, Kanyshkova TG, Doronin BM, Tyshkevich OB, Buneva VN, Boiko 864 AN, Gusev EI, Favorova OO, Nevinsky GA. Hydrolysis of myelin basic protein by 865 polyclonal catalytic IgGs from the sera of patients with multiple sclerosis. J Cell Mol Med. $866 \quad 2004 ; 8: 359-368$. 
22. Polosukhina DI, Buneva VN, Doronin BM, et al. Hydrolysis of myelin basic protein

868 by $\operatorname{IgM}$ and $\operatorname{IgA}$ antibodies from the sera of patients with multiple sclerosis. Med Sci 869 Monit. 2005;11:BR266- BR72.

870 23. Polosukhina DI, Kanyshkova TG, Doronin BM, Tyshkevich OB, Buneva VN, Boiko 871 AN, Gusev EI, Favorova OO, , Nevinsky GA. Metal-dependent hydrolysis of myelin basic 872 protein by IgGs from the sera of patients with multiple sclerosis. Immunol Lett. $873 \quad 2006 ; 103: 75-81$.

874 24. Baranovskii AG, Kanyshkova TG, Mogelnitskii AS, Naumov VA, Buneva VN, 875 Gusev EI, Boiko AN, Zargarova TA, Favorova OO, Nevinsky GA. Polyclonal antibodies 876 from blood and cerebrospinal fluid of patients with multiple sclerosis effectively hydrolyze 877 DNA and RNA. Biochemistry. 1998;63:1239-1248.

878 25. Baranovskii AG, Ershova NA, Buneva VN, Kanyshkova TG, Mogelnitskii AS, 879 Doronin BM, Boiko AN, Gusev EI, Favorova OO, Nevinsky GA. Catalytic heterogeneity 880 of polyclonal DNA-hydrolyzing antibodies from the sera of patients with multiple $881 \quad$ sclerosis. Immunol Lett. 2001;76:163-167.

882 26. Parkhomenko TA, Doronin VB, Castellazzi M, Padroni M, Pastore M, Buneva VN, 883 Granieri E, Nevinsky GA. Comparison of DNA-hydrolyzing antibodies from the 884 cerebrospinal fluid and serum of patients with multiple sclerosis. PLoS ONE. $885 \quad 2014 ; 9: \mathrm{e} 93001$.

886 27. Doronin VB, Parkhomenko,TA, Castellazzi M, Padroni M, Pastore M, Buneva VN, 887 Granieri E, Nevinsky GA. Comparison of antibodies hydrolyzing myelin basic protein 888 from the cerebrospinal fluid and serum of patients with multiple sclerosis. PLoS ONE. $889 \quad 2014 ; 9: \mathrm{e} 107807$.

890 28. Doronin VB, Parkhomenko TA, Castellazzi M, Cesnik E, Buneva VN, Granieri E, 891 Nevinsky GA. Comparison of antibodies with amylase activity from cerebrospinal fluid 892 and serum of patients with multiple sclerosis. PLoS ONE. 2016;11:e0154688. 
29. Croxford AL, Kurschus FC, Waisman A. Mouse models for multiple sclerosis:

894 Historical facts and future implications. Bochim Biophys Acta. 2011;1812:177-83.

895 30. Miller SD, Karpus WJ, Davidson TS. Experimental Autoimmune Encephalomyelitis 896 in the Mouse. Curr Protoc Immunol Chapter: Unit-151, 2007.

897 31. Mouse EAE models Overview and Model Selection Hooke Laboratories, Inc, 2011$898 \quad 2013$.

899 32. Kenneth M. Janeway's Immunobiology (8th ed). New York; Garland Science,_2012.

900 33. Klotz L, Kuzmanov I, Hucke S, Gross CC, Posevitz V, Dreykluft A, Schulte901 Mecklenbeck A, Janoschka C, et al. B7-H1 shapes T-cell-mediated brain endothelial cell 902 dysfunction and regional encephalitogenicity in spontaneous CNS autoimmunity. Proc Natl 903 Acad Sci USA. 2016;113:E6182-E6191.

904 34. Doronin VB, Korablev A, Toporkova LB, Aulova KS, Buneva VN, Budde T, Meuth 905 SG, Orlovskaya IA, Popova NA, Nevinsky GA. Changes in several disease parameters 906 including abzymes and hematopoietic progenitor colony formation in brain inflammation 907 and demyelination. J Neurol Neurol Disord. 2017;3:302.

908 35. Aulova KS, Toporkova LB, Lopatnikova JA, Alshevskaya AA, Sedykh SE, Buneva 909 VN, Budde T, Meuth SG, Popova NA, Orlovskaya IA, Nevinsky GA. Changes in cell 910 differentiation and proliferation lead to production of abzymes in EAE mice treated with 911 DNA-Histone complexes. J Cell Mol Med. 2018;22:5816-5832.

912 36. Sinohara H, Matsuura K. Does catalytic activity of Bence-Jones proteins contribute to 913 the pathogenesis of multiple myeloma? Appl Biochem Biotechnol. 2000;83:85-92.

914 37. Kozyr AV, Kolesnikov AV, Aleksandrova ES, et al. Novel functional activities of 915 anti-DNA autoantibodies from sera of patients with lymphoproliferative and autoimmune 916 diseases Appl Biochem Biotechnol. 1998;75:45-61.

917 38. Nevinsky GA, Buneva VN. Catalytic antibodies in healthy humans and patients with 918 autoimmune and viral pathologies. J Cell Mol Med. 2003;7:265-276. 
919 39. Founel S, Muller S. Antinucleosome antibodies and T-cell response in systemic lupus

920 erythematosus. Ann MedInterne (Paris). 2002;153:513-519.

921 40. Boiko AN, Favorova OO. Multiple sclerosis: molecular and cellular mechanisms.

922 Mol Biol (Mosk). 1995;29:727-74.

923 41. Baulina N, Kulakova O, Kiselev I, Osmak G, Popova E, Boyko A, Favorova O.

924 Immune-related miRNA expression patterns in peripheral blood mononuclear cells differ in

925 multiple sclerosis relapse and remission. J Neuroimmunol. 2018;317:67-76.

926 42. Baulina N, Osmak G, Kiselev I, Popova E, Boyko A, Kulakova O, Favorova O .

927 MiRNAs from DLK1-DIO3 Imprinted Locus at 14q32 are Associated with Multiple

928 Sclerosis: Gender-Specific Expression and Regulation of Receptor Tyrosine Kinases

929 Signaling. Cells. 2019:8:133.

930

931

932

933

934

935

936

937

938

939

940

941

942

943

944

945 


\section{$947 \quad$ Figure legends}

948 Fig. 1. Overtime changes in weight (A) and proteinuria-relative concentration proteins

949 in the urine of Th mice (B) before and after mice treatment-immunization with MOG.

950 Fig. 2. Overtime changes of the average content of bone marrow progenitor colony-forming units

951 for untreated and MOG-treated mice (7 mice of each group): BFU-E (A), CFU-E (B), CFU-GM (C),

952 and CFU-GEMM (D) as well as bone marrow B (E) and T (F) cells.

953 Fig. 3. Overtime changes in B lymphocyte proliferation (\%) in the blood (A), thymus (B), 954 spleen (C), and lymph nodes (D) for untreated and MOG-treated mice. The error in B 955 lymphocyte determination from three independent experiments in the case of each mouse 956 of every group (7 mice) did not exceed $7-10 \%$.

957

958 Fig. 4. Overtime changes in CD4 lymphocyte proliferation (\%) in bone marrow (A), blood (B), thymus (C), spleen (D), and lymph nodes (E) for untreated and MOG-treated mice.

960 The error in CD4 lymphocyte determination from three independent experiments in the 961 case of each mouse of every group (7 mice) did not exceed 7-10\%.

962

963 Fig. 5. Overtime changes in CD8 lymphocyte proliferation (\%) in bone marrow (A), blood 964 (B), thymus (C), spleen (D), and lymph nodes (E) for untreated and MOG-treated mice.

965 The error in CD4 lymphocyte determination from three independent experiments in the 966 case of each mouse of every group (7 mice) did not exceed $7-10 \%$.

967

968 Fig. 6. In time changes in the relative concentration of Abs to DNA (A), MBP (B), and 969 MOG (C) in Th mice untreated and treated with MOG. All antibody concentrations were 970 measured by ELISA. The error in the determination of the concentration from three 
971 independent experiments in the case of each mouse of every group (7 mice) did not exceed $972 \quad 7-10 \%$.

973 Fig. 7. The homogeneity analysis by SDS-PAGE of $12 \mu \mathrm{g} \operatorname{IgG}_{\operatorname{mix}}$ under non-reducing 974 conditions (A); silver staining; panel A shows the position of IgGs. The relative activities 975 (RA, \%) in the hydrolysis of DNA (o) and MBP ( $\mathbf{a})$ by eluates of gel fragments were 976 estimated using the extracts of gel fragments $(2-3 \mathrm{~mm})(\mathbf{B})$. Complete hydrolysis of these 977 substrates after their incubation with eluates for $24 \mathrm{~h}$ of was taken for $100 \%$ (A). The errors 978 of the RAs determinations from two independent experiments did not exceed 7-10\%.

979 Fig. 8. In time changes in the relative average (RAs) activities of Th IgGs before and after 980 mice treatment (immunization) with MOG in the hydrolysis of DNA (A), MBP (B), and 981 MOG (C); RA of mice IgGs corresponding to 7 individual mice of every group. The error 982 in the individual RA determination for every mouse of each group does not exceed 7-10\%. 
Figures
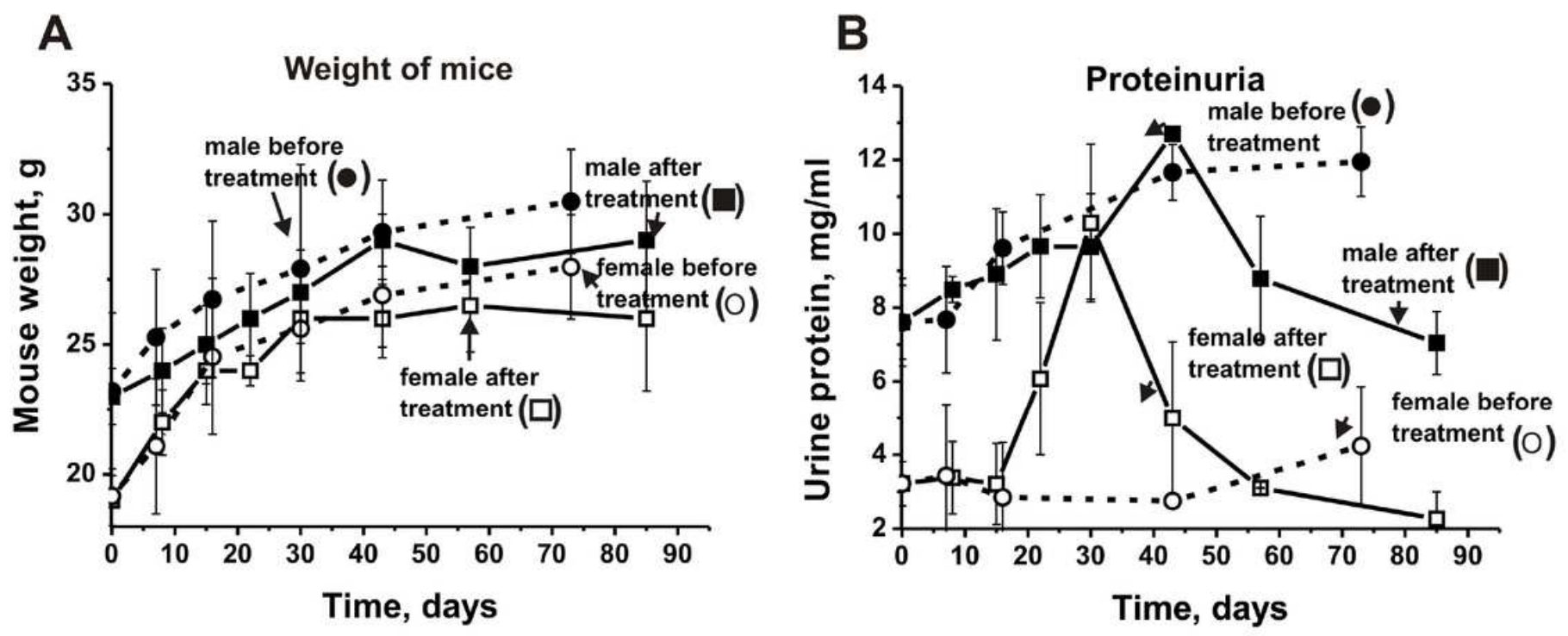

Fig. 1

Figure 1

Overtime changes in weight $(A)$ and proteinuria-relative concentration proteins in the urine of Th mice (B) before and after mice treatment-immunization with MOG. 

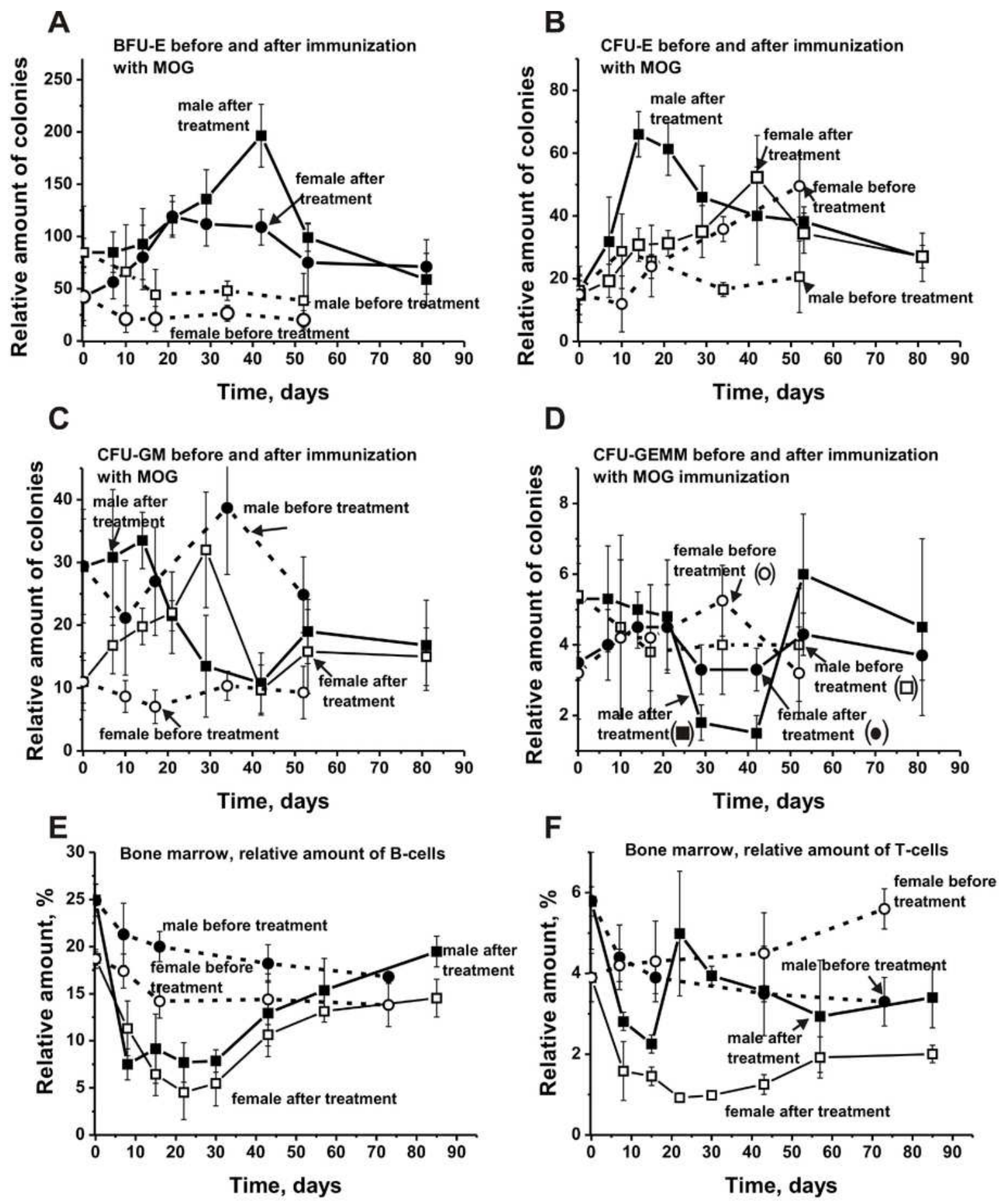

Fig. 2

\section{Figure 2}

Overtime changes of the average content of bone marrow progenitor colony-forming units for untreated and MOG-treated mice (7 mice of each group): BFU-E (A), CFU-E (B), CFU-GM (C), and CFU-GEMM (D) as well as bone marrow $B(E)$ and $T(F)$ cells. 

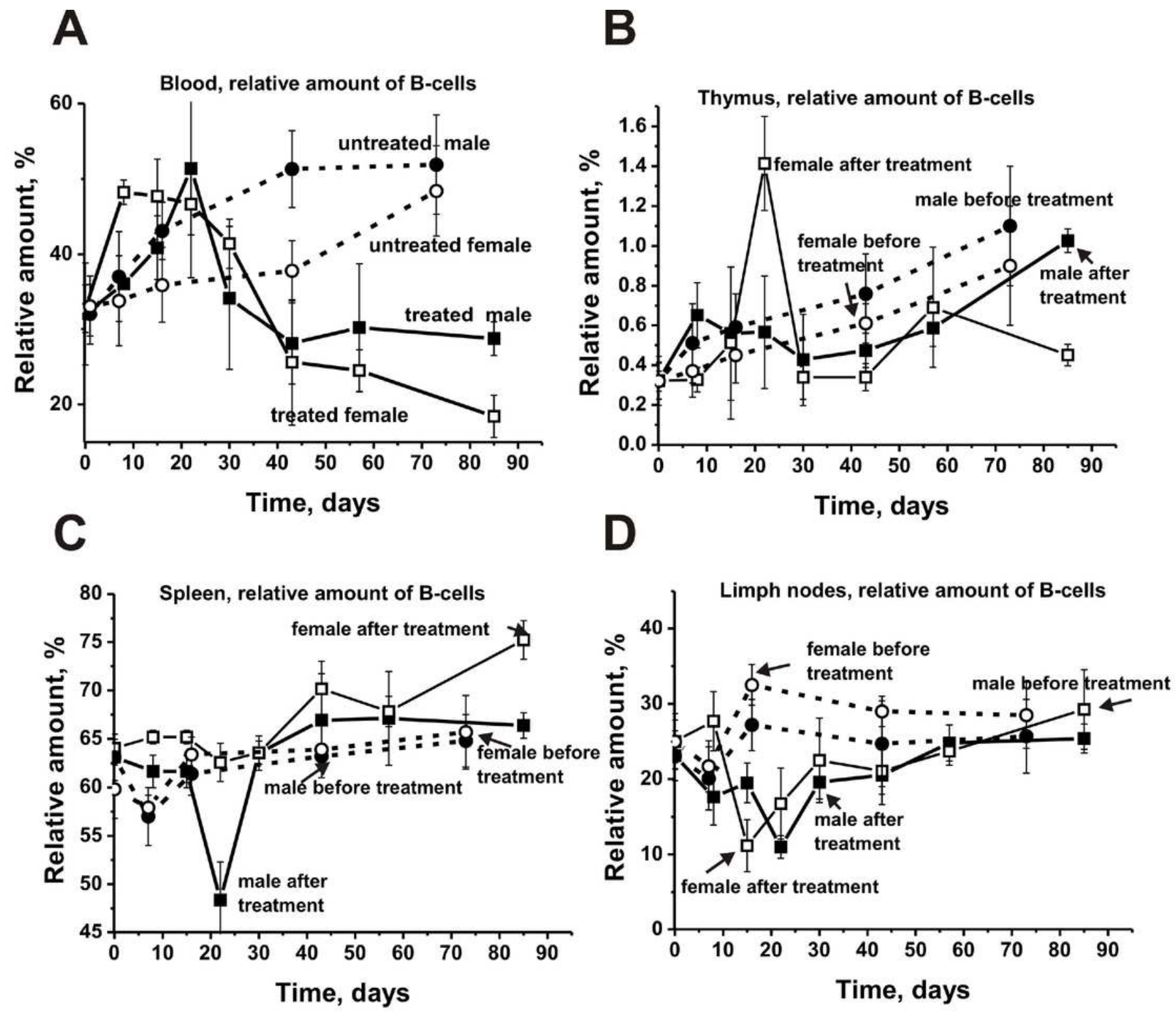

\section{Fig. 3}

Figure 3

Overtime changes in B lymphocyte proliferation (\%) in the blood (A), thymus (B), spleen (C), and lymph nodes (D) for untreated and MOG-treated mice. The error in B lymphocyte determination from three independent experiments in the case of each mouse of every group (7 mice) did not exceed $7-10 \%$. 
A Bone marrow, relative amount of CD4-cells

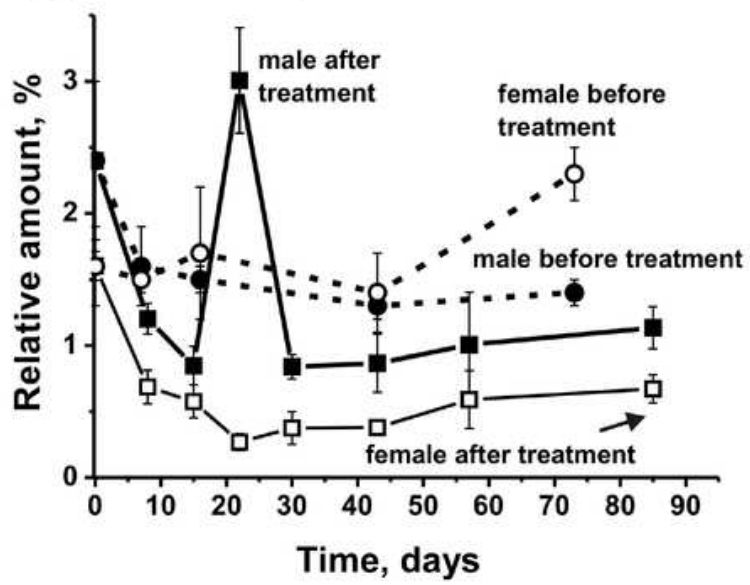

C

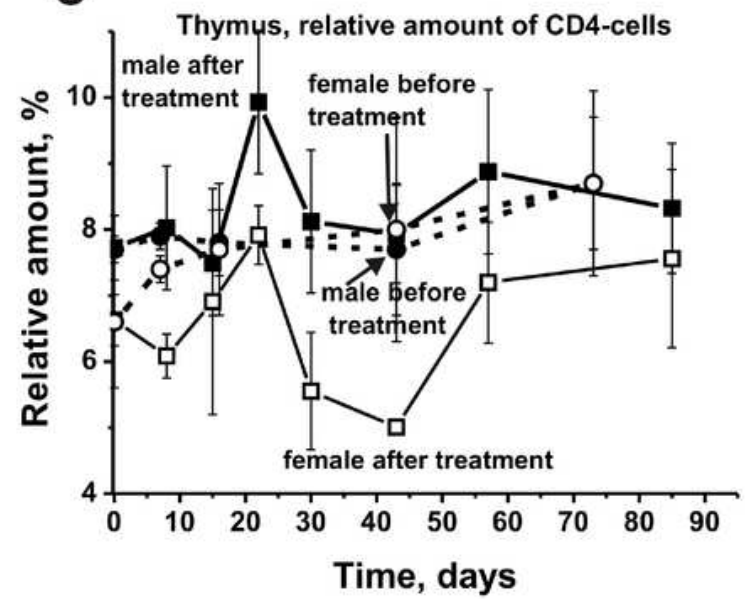

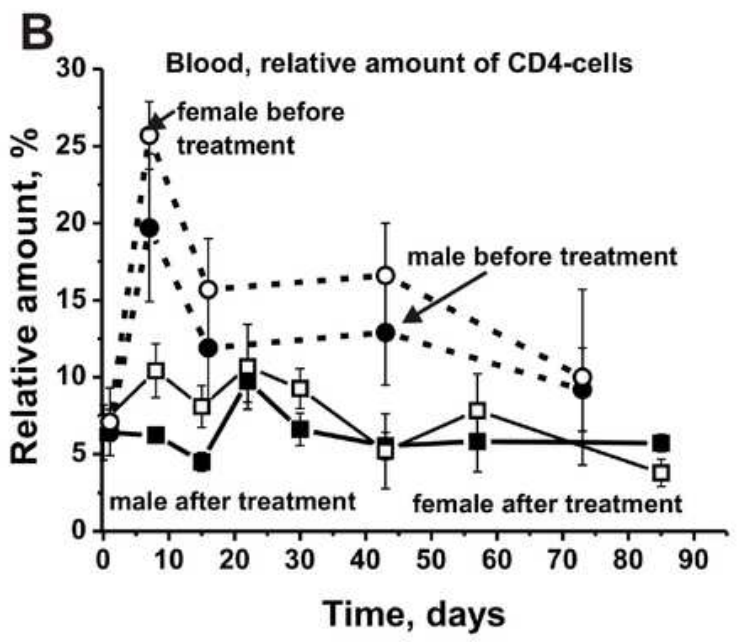

D

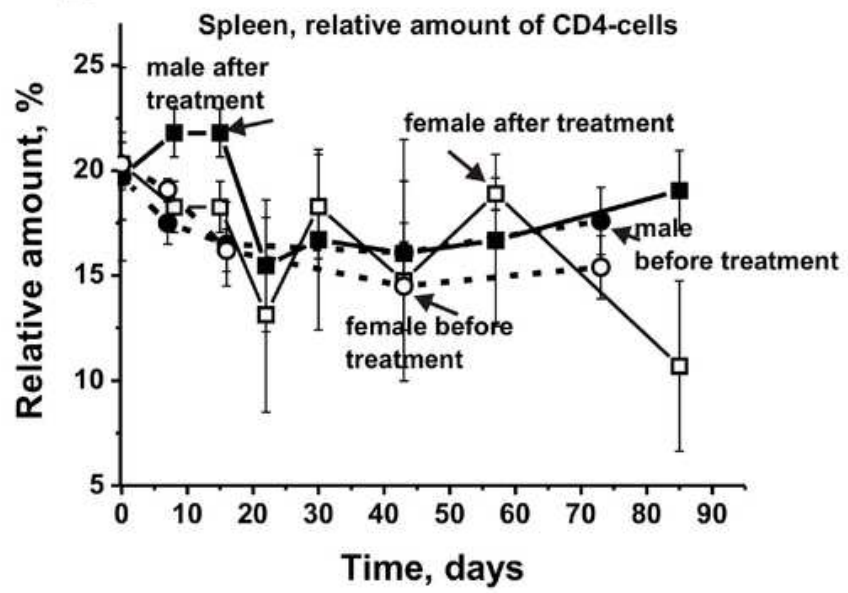

Fig. 4

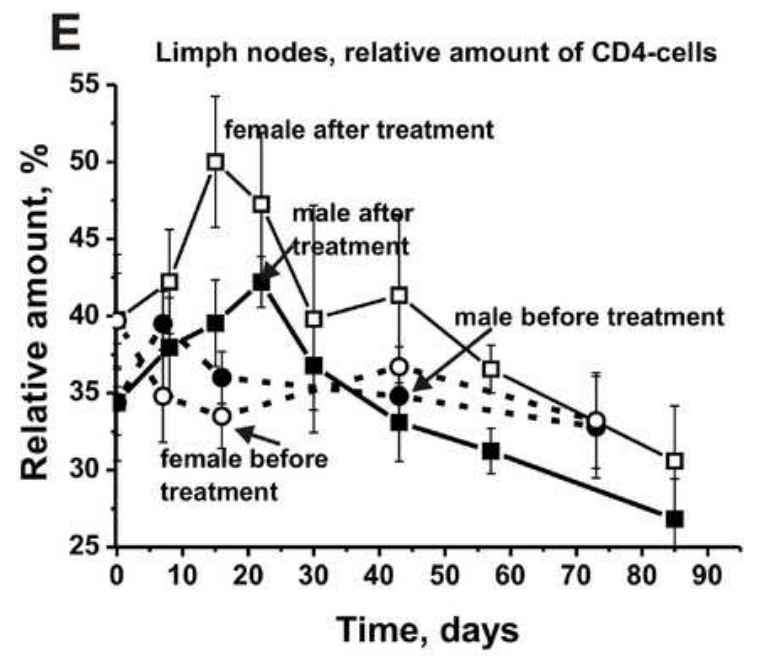

Figure 4

Overtime changes in CD4 lymphocyte proliferation (\%) in bone marrow (A), blood (B), thymus (C), spleen (D), and lymph nodes (E) for untreated and MOG-treated mice. The error in CD4 lymphocyte determination from three independent experiments in the case of each mouse of every group (7 mice) did not exceed 7$10 \%$. 

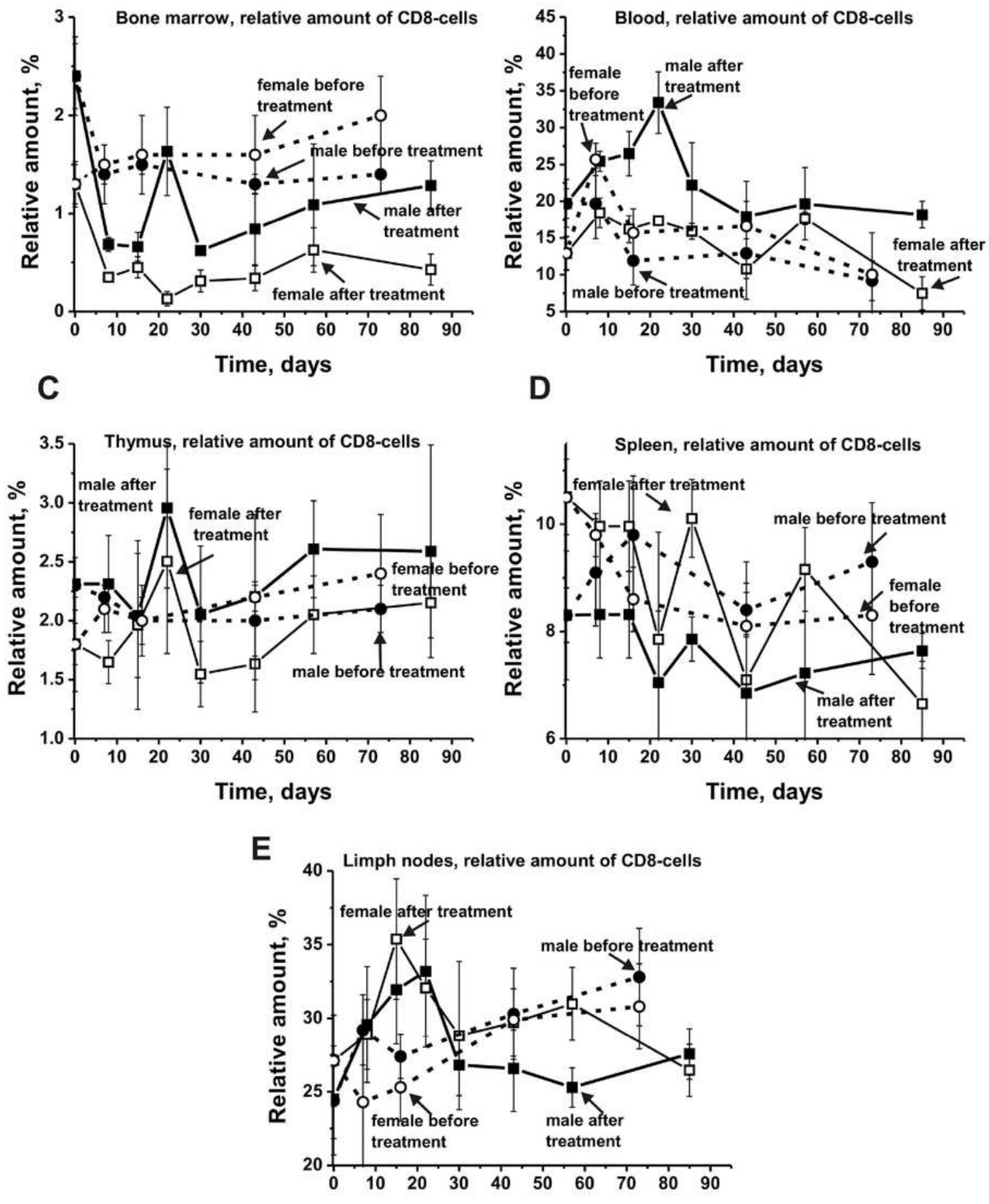

Fig. 5

Time, days

\section{Figure 5}

Overtime changes in CD8 lymphocyte proliferation (\%) in bone marrow (A), blood (B), thymus (C), spleen (D), and lymph nodes (E) for untreated and MOG-treated mice. The error in CD4 lymphocyte determination from three independent experiments in the case of each mouse of every group (7 mice) did not exceed 7$10 \%$. 
A

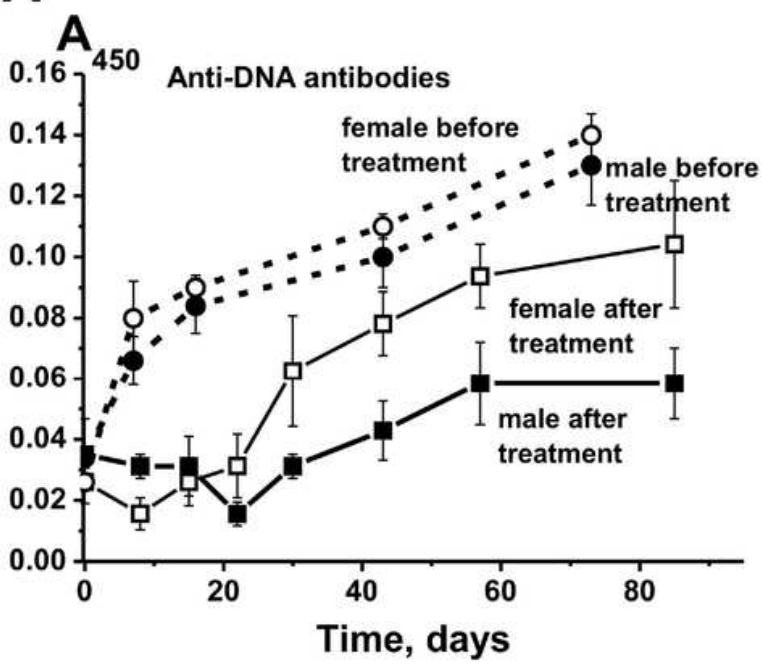

B

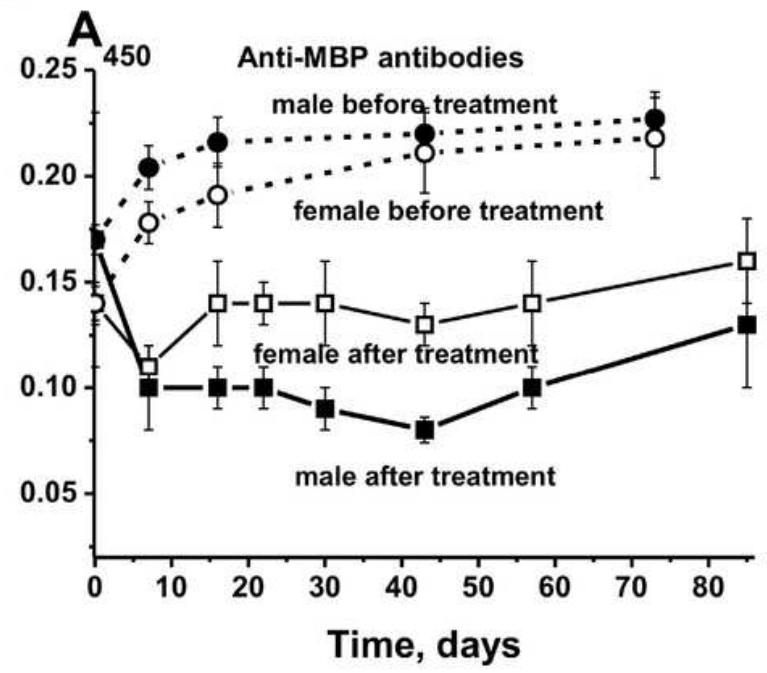

C

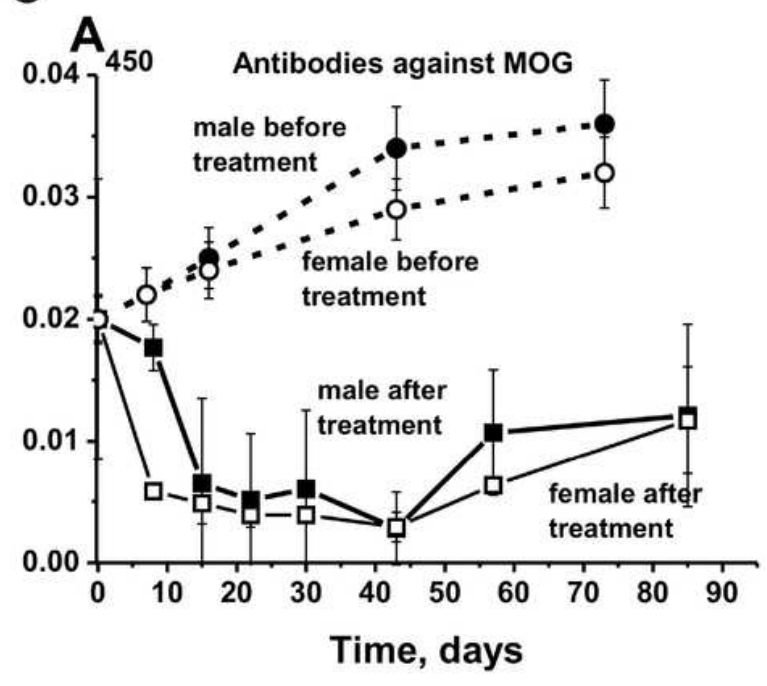

\section{Fig. 6}

\section{Figure 6}

In time changes in the relative concentration of Abs to DNA (A), MBP (B), and MOG (C) in Th mice untreated and treated with MOG. All antibody concentrations were measured by ELISA. The error in the determination of the concentration from three independent experiments in the case of each mouse of every group (7 mice) did not exceed $7-10 \%$. 


\section{$\lg G$}

${ }^{A}$

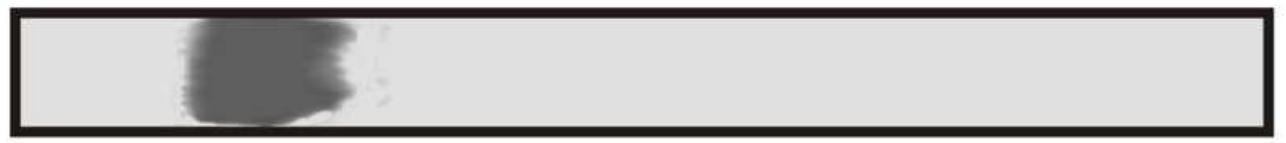

\section{OA, $\%$}

B

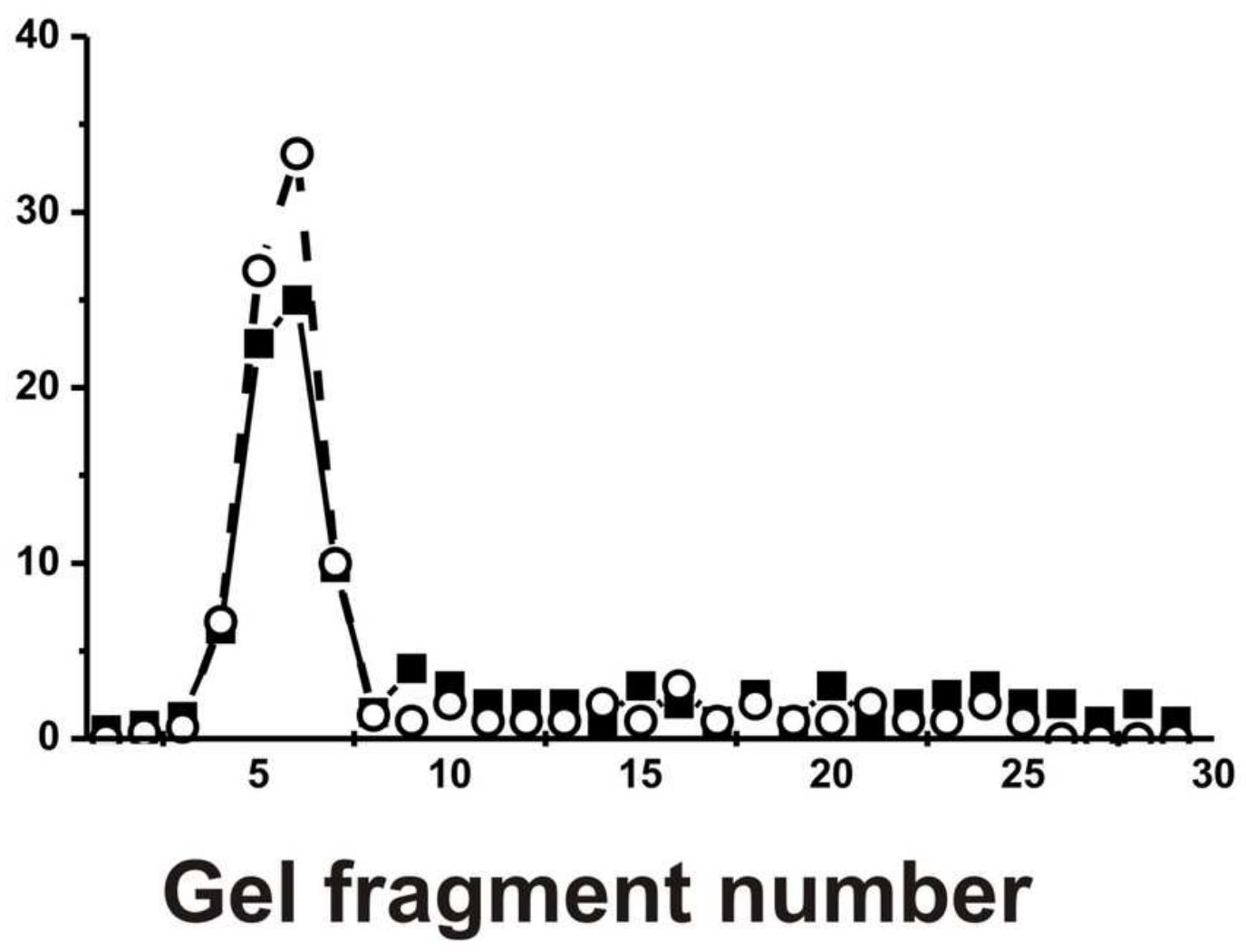

\section{Figure 7}

Figure 7

The homogeneity analysis by SDS-PAGE of $12 \mathrm{gg}$ IgGmix under non-reducing conditions (A); silver staining; panel A shows the position of IgGs. The relative activities (RA, \%) in the hydrolysis of DNA (o) and MBP $(\mathbb{\nabla})$ by eluates of gel fragments were estimated using the extracts of gel fragments $(2-3 \mathrm{~mm})$ (B). Complete hydrolysis of these substrates after their incubation with eluates for $24 \mathrm{~h}$ of was taken for $100 \%$ (A). The errors of the RAs determinations from two independent experiments did not exceed 7$10 \%$. 

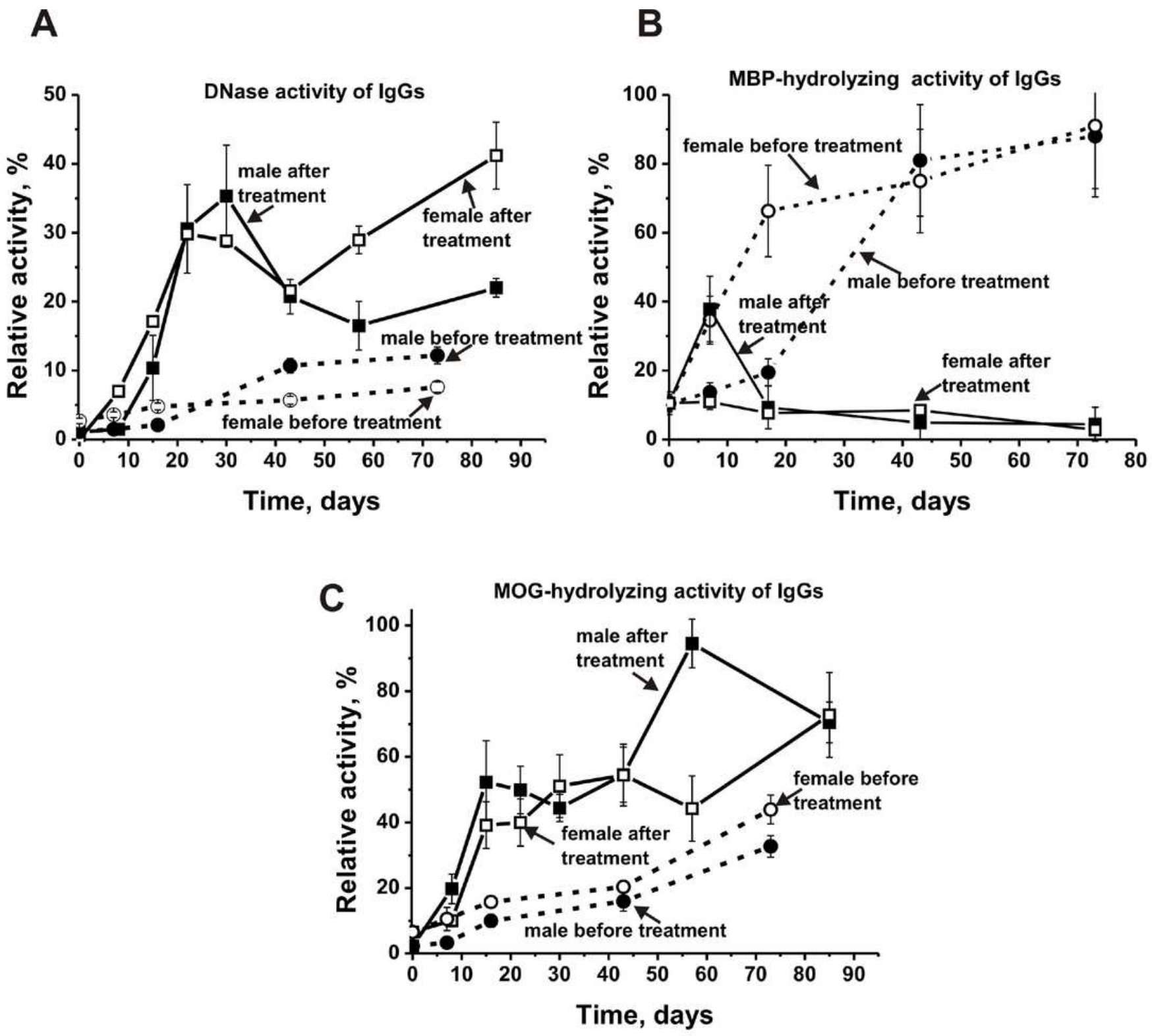

\section{Fig. 8}

\section{Figure 8}

In time changes in the relative average (RAs) activities of Th IgGs before and after mice treatment (immunization) with MOG in the hydrolysis of DNA (A), MBP (B), and MOG (C); RA of mice IgGs corresponding to 7 individual mice of every group. The error in the individual RA determination for every mouse of each group does not exceed $7-10 \%$.

\section{Supplementary Files}

This is a list of supplementary files associated with this preprint. Click to download. 